\title{
Gamified Mobile Applications for Improving Driving Behavior: A Systematic Mapping Study
}

\author{
Abderrahim El hafidy (D), Taoufik Rachad (D), Ali Idri ${ }^{(D)}$, and Ahmed Zellou \\ Software Project Management Research Team, ENSIAS, Mohammed V University in Rabat, Rabat, Morocco \\ Correspondence should be addressed to Taoufik Rachad; taoufik.rachad@um5.ac.ma
}

Received 18 November 2020; Revised 30 May 2021; Accepted 31 July 2021; Published 16 August 2021

Academic Editor: Sergio Mascetti

Copyright (c) 2021 Abderrahim El hafidy et al. This is an open access article distributed under the Creative Commons Attribution License, which permits unrestricted use, distribution, and reproduction in any medium, provided the original work is properly cited.

\begin{abstract}
Many research works and official reports approve that irresponsible driving behavior on the road is the main cause of accidents. Consequently, responsible driving behavior can significantly reduce accidents' number and severity. Therefore, in the research area as well as in the industrial area, mobile technologies are widely exploited in assisting drivers in reducing accident rates and preventing accidents. For instance, several mobile apps are provided to assist drivers in improving their driving behavior. Recently and thanks to mobile cloud computing, smartphones can benefit from the computing power of servers in the cloud for executing machine learning algorithms. Therefore, many mobile applications of driving assistance and control are based on machine learning techniques to adjust their functioning automatically to driver history, context, and profile. Additionally, gamification is a key element in the design of these mobile applications that allow drivers to develop their engagement and motivation to improve their driving behavior. To have an overview concerning existing mobile apps that improve driving behavior, we have chosen to conduct a systematic mapping study about driving behavior mobile apps that exist in the most common mobile apps repositories or that were published as research works in digital libraries. In particular, we should explore their functionalities, the kinds of collected data, the used gamification elements, and the used machine learning techniques and algorithms. We have successfully identified 220 mobile apps that help to improve driving behavior. In this work, we will extract all the data that seem to be useful for the classification and analysis of the functionalities offered by these applications.
\end{abstract}

\section{Introduction}

A road accident is defined as an accident on a public road that involves at least one victim and one vehicle [1]. According to the WHO (World Health Organization), 1.35 million people are killed and up to 50 million injuries are recorded each year [2]. The number of road accidents continues to increase, mainly due to the rapid urban growth and the exponential growth of the vehicle fleet [3]. Statistics predict that road accidents will increase by $65 \%$ and become the fifth leading cause of death by 2030 [3]. These accidents generally cause very significant material and human damage [4].

Despite the efforts made by national and international organizations for driver awareness and encouragement to responsible driving, the aberrant behavior of drivers remains the main cause of most road accidents [5-7]. According to
Lequeux and Leblud [4], the main causes of accidents are human factors with a rate of $72 \%$, environmental conditions with a rate of $18 \%$, road infrastructure with a rate of $9 \%$, and the condition of the vehicle with a rate of $2 \%$. According to Charbit [8], human factors are the main causes of accidents with $76.70 \%$, environmental factors with $18.80 \%$, and other vehicle-related factors with $4.40 \%$.

For accident reduction and prevention, mobile technologies are widely exploited in the control, monitoring, and assistance of drivers [3], especially smartphones which are equipped with several sensors that provide the possibility to collect data about vehicles and drivers [9]. The collected data can be analyzed via machine learning algorithms to extract patterns and models about driving behavior, driving style, driving skills, and accident prediction. All that will make mobile apps more intelligent by providing automatic 
adaptation to the context, the profile, and the past actions of drivers. These mobile apps should not provide just insight into drivers but they will encourage drivers to continuously improve their behavior on the road. Therefore, adding gamification in driving mobile apps will allow them to ensure engagement and increase the motivation of drivers to improve their behavior [10].

The objective of this work is to have an overview of mobile applications that use machine learning and gamification for improving the behavior of drivers on the road. Therefore, we conduct a systematic mapping study of gamified mobile apps that attempt to improve driving behavior [11].

Out of a total of 873 mobile apps in mobile repositories and 25229 papers in digital libraries, 220 mobile apps were selected, analyzed, and reviewed after examining compliance with the inclusion and exclusion criteria based on the review of their titles, descriptions, abstract, and screenshots.

The remainder of the article is organized as follows. Section 2 provides the background of this work, by giving the contributions of mobile technologies, machine learning, and gamification in the improvement of driving behavior. Section 3 presents the methodology adopted to conduct a systematic mapping study. Section 4 presents and discusses the main results of this study. Section 5 presents the limitations of this study. And finally, Section 6 presents conclusions and future works.

\section{Background}

2.1. Mobile Technologies for Driving Behavior Improvement. Mobile technologies have transformed the way we live, work, travel, learn, and shop. Therefore, all fundamental human activities have been affected positively by mobile technologies, allowing several daily tasks to be realized simply and efficiently. Many mobile technologies and techniques are exploited in the control, monitoring, and assistance of drivers [12]. IOMT (Internet of Mobile Things), ADAS (advanced driver-assistance systems), and smartphones are the key elements of these technologies $[12,13]$.

Recently, the Internet of Things (IoT) and the Internet of Mobile Things (IOMT) are fundamentally changing the world by allowing multiple (mobile) devices to communicate and exchange data with each other and make decisions without human interventions [14]. Therefore, IOMT technology is the key element in the fabrication of intelligent vehicles equipped with safety sensors that allow avoiding many accidents [3].

Advanced driver assistance systems (ADASs) were developed to prevent and avoid dangerous driving situations by warning drivers by visual, audible, or haptic (vibration) signal of danger [15]. The development of the first driverassistance systems began with the antilock braking system (ABS) in the late 1970s of the twentieth century [16]. The objective of these technologies is to reduce the consequences of an accident, to prevent traffic accidents, and soon to facilitate fully autonomous driving [17]. ADASs help the driver to assimilate information and help to avoid distractions and reduced activity [18]. This allows drivers to continue to focus on the road and keep their hands on the wheel while receiving important instructions and information [19].

Smartphones as the most affordable ubiquitous devices are becoming the most cost-effective and practical method for collecting driving behavior data in real-time [20]. Moreover, many mobile apps improve driving by sending notifications in real-time while driving, generating a periodic trip report at the end of each trip, help in drivers' training and learning, and so on [21]. However, the difficulty lies in how to analyze and understand the collected data and make intelligent decisions [22]

\subsection{Contribution of Machine Learning in the Analysis of} Driving Data. Machine learning (ML) techniques are widely used to extract knowledge from a large dataset. Many ML tasks such as classification, regression, clustering, and association can be combined or used individually to analyze data and extract new patterns. Recently, ML techniques can be used to ensure intelligent interactions with mobile users by adapting mobile apps interfaces and actions to mobile users' contexts, profiles, and interaction history [23].

Many research works about driving behavior have used ML techniques to analyze data obtained from smartphone sensors such as accelerometers, gyroscopes, and rotation vectors [24]. Ferreira et al. [25] studied the exploitation of Android smartphone sensors and machine learning algorithms to detect aggressive driving events and subsequently classify drivers' behavior. Eren et al. [26] have proposed a mobile app to classify drivers behavior according to risky driving events, using smartphone sensors like accelerometer, gyroscope, and magnetometer, and the application detects sharp turns, sudden lane changes, acceleration, and braking events and uses a Bayesian classifier to determine safe or unsafe driver behavior. Jacobé de Naurois et al. [27] have used machine learning techniques for detecting driver drowsiness. Chhabra et al. [28] have used ML techniques for accident prevention by detecting driver fatigue, drowsiness, inattention, or intoxication in real-time and also helped to classify drivers' behavior into aggressive or nonaggressive. Ping et al. [29] have studied the relationship between driving behavior and fuel consumption using ML techniques. Also, Shit [30] has used ML techniques with crowdsourced data to provide intelligent services such as real-time traffic monitoring, traffic prediction, travel time prediction, and travel activity tracking. Finally, Kashevnik et al. [31] have used ML algorithms as artificial neural network, decision tree, hidden Markov model, and SVM to recognize the behavior of drivers by analyzing driving data provided by smartphone sensors.

2.3. Gamification for Driver's Engagement. Gamification is the use of game design elements in a nongame context. It will make repetitive and monotonous tasks more fun and more enjoyable; therefore, it will allow promoting the active interest of users and their engagement to improve their behaviors [10, 32-35]. Thus, gamification techniques are considered as an important element in the design of mobile 
apps that aim to improve user skills, engagements, or behaviors.

The use of gamification techniques in the field of transportation and driving aims to quantify the success on a predetermined overall objective such as improving driving behavior, reducing fuel consumption, adopting eco-driving habits, and awareness of good driving [36]. Magaña and Organero [37] studied the impact of using gamification for improving eco-driving learning; they have concluded that the use of gamification elements such as the score and achievements systems promotes safe driving. Wells et al. [38] affirmed that the use of gamification elements such as score/ point and level encourages users to think about their driving behaviors and engages them in sustainable safe driving behavior. To study the effect of gamification on behavior change, motivation, and user experience, Fitz-Walter et al. [39] investigated and compared gamified and nongamified versions of an application that aims to allow drivers to record their practice sessions in a logbook. Finally, Diewald et al. [40] have studied the use of gameful design in the automotive domain by examining examples of gamified applications and exploring the different available game design mechanics.

\section{Methodology}

To have an overview concerning existing mobile apps about driving behavior, we conducted a systematic mapping study [11] that will lead to the identification and analysis of driving mobile apps that exist in the common mobile repositories or that were published as research works in the common digital libraries. A systematic mapping study allows having an overview of any research subject by offering a count and classification of results already published in scientific or industrial fields [41]. It will help in structuring the research topic in question and will also allow conducting subsequent research work as systematic literature review [42, 43].

In general, an SMS is carried out in five fundamental steps: formulate research questions, extract keywords and define search strings, query data sources, apply exclusion/ inclusion criteria, and finally extract data about selected works [42]. As illustrated in Figure 1, two research methodologies were adopted in searching for mobile apps, the first one searches for mobile apps in the common mobile app's repositories and the second methodology searches for mobile apps that are published as research works in the common digital libraries.

In the first step, some research questions are used to define the purpose of the study, and the answers to these questions will help in structuring the research topic in question and will also allow conducting properly subsequent research work $[42,43]$. In the second step, the PICO model (population, interventions, comparison, and outcomes) is used to identify keywords and formulate search strings. Population refers to a specific problem, role, type, or area of application. Interventions refer to the technology or software methodology that addresses a specific problem. The comparison identifies the technologies, techniques, tools, methods, or strategies to extract and compare. Finally, outcomes are related to the factors of the importance of the intervention for practitioners $[42,43]$. In the third step, we describe all possible data sources such as mobile apps repositories and digital libraries [44]. In the fourth step, inclusion and exclusion criteria should be used to select only relevant works corresponding to the subject of the study; these criteria will be applied to the title and the abstract or the descriptions of each selected work. The fifth step will be devoted to the data extraction from the selected apps. The extracted data should allow answering the research questions specified in the first step $[42,43]$.

3.1. Research Questions. The objective of this study is to present an overview of the use of machine learning and gamification in the design and realization of mobile applications related to driving behavior control. To clearly define this objective, six main research questions with the corresponding hypothesis are provided in Table 1.

3.2. Search String and Keywords. To find the keywords and search string of the study, we adopt the PICO (population, intervention, comparison, and outcomes) methodology presented in [45]. Table 2 illustrates the terms assigned to each component of the PICO model. For extracting the keywords, we used the roles proposed in [46] which consist of classifying the keywords in many sets, such as each one corresponds to one component of the PICO model. Table 3 presents the extracted keywords. After defining the keywords sets, we have classified them into four groups, and each group contains terms that are similar, synonyms, or that belong to the same radical. Table 4 presents the obtained groups.

The definitive search string for digital libraries is obtained by concatenating words from the four groups as follows: (mobile OR smartphone OR "mobile application" OR “mobile app") AND (driver OR driving OR car OR vehicle) AND (behavior OR comportment OR style) AND (gamified OR gamification OR engagement OR motivation).

For searching in mobile apps repositories, we used the same keywords used in the construction of the search string.

3.3. Querying Data Sources. In this work, we considered mainly gamified mobile apps for driving behavior control and improvement that were published as research works in the common digital libraries that are the most used to publish in the Software Engineering area [47], namely, IEEE Xplore, ACM Digital Library, ScienceDirect, and Springer Link. However, the search string needs some slight modifications to adapt it to the research rules of each digital library.

Also, we considered mobile apps deployed in the repositories Google Play Store and App Store. The two selected mobile apps repositories were selected based on their popularity and market share. In 2020, Android dominates the market with a share of $85.4 \%$, followed by iOS with a share of $14.6 \%$ [48]. The web scraping technique is adopted to extract information about mobile apps that match to 


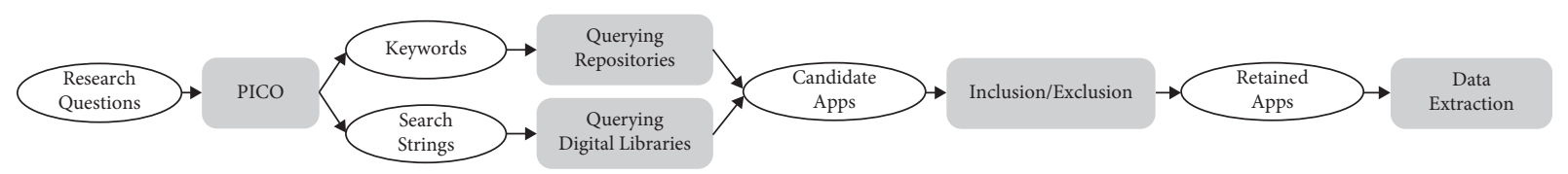

FIgURE 1: SMS process description.

TABLE 1: Research questions and hypotheses.

\begin{tabular}{lll}
\hline ID & Research questions & Motivation \\
\hline
\end{tabular}

Which gamified mobile apps related to driving behavior improvement are

Q1 apps repositories and digital libraries?

To identify which existing gamified mobile apps are related to driving behavior and to know when and where these mobile apps were developed.

What are the functionalities offered by these applications?

Q3

What data are collected and how they were collected?

In which phase of driving the selected mobile apps took part?

What machine learning models, tasks, and Q5 algorithms are used to analyze the collected data?

Q6

What are the gamification elements used by selected applications?
To have an inventory of the functionalities provided by selected applications.

To identify the type of collected data, either driving data, profile data, context data, or health data.

To know if the selected mobile apps can be (H4) All the selected mobile apps collect used before driving, while driving, or after data about drivers before, during, and after driving.

To determine the most used ML models, tasks, and algorithms to analyze the collected data.

To identify the most used gamification elements in the design of selected applications.

(H6.2) All the selected mobile apps use a
Hypothesis

(H1.1) The existing mobile apps for driving behavior improvement available in the Android platform are more than those available in other platforms.

(H1.2) Several mobile apps for driving behavior improvement are available in many versions for all platforms (Android, iOS, and Windows phone).

(H2) There is no significant difference between the functionalities offered by the selected mobile apps.

(H3) All the selected mobile apps collect data about the driver's profile, context, and health. driving.

(H5) Classification is the most used ML task in driving behavior analysis.

(H6.1) There is no significant difference between the use of gamification elements in selected mobile apps. combination of several gamification elements to ensure driver engagement and motivation.

TABLE 2: PICO components for gamified mobile apps about driving behavior improvement.

\begin{tabular}{|c|c|}
\hline Components & Description \\
\hline Population & $\begin{array}{l}\text { Mobile application for improvement of driver behavior } \\
\text { (i) Intelligent (user-oriented, adaptive, reactive, and responsive) mobile applications }\end{array}$ \\
\hline Interventions & $\begin{array}{l}\text { (ii) Gamified (gamification) mobile apps } \\
\text { (iii) machine learning-based model }\end{array}$ \\
\hline Comparison & $\begin{array}{l}\text { We compare mobile apps related to the improvement of driving behavior by identifying and comparing their functionalities } \\
\text { and by comparing the techniques used to collect and analyze driver's behavior data } \\
\text { (i) Car or vehicle driver behavior improvement using mobile }\end{array}$ \\
\hline Outcomes & $\begin{array}{l}\text { (ii) Recognize driver's style and comportment using a smartphone } \\
\text { (iii) Improve driver's engagement and motivation mobile apps }\end{array}$ \\
\hline
\end{tabular}

TABle 3: Sets of the extracted keywords from the PICO components.

\begin{tabular}{lcc}
\hline Set & Components & Keywords \\
\hline 1 & Population & Mobile application, improvement, driver, behavior \\
2 & Interventions & Intelligent, mobile application, gamified, gamification machine learning \\
3 & Comparison & Mobile app, driving, behavior, collect, analyze, driver, behavior, data \\
4 & Outcomes & Car, driver, vehicle, behavior, improvement, mobile, driver, style, comportment, smartphone, driver, engagement, \\
& motivation, mobile apps \\
\hline
\end{tabular}


Table 4: Categorization of identified terms.

\begin{tabular}{lcccc}
\hline Terms & $\mathrm{G} 1$ & $\mathrm{G} 2$ & $\mathrm{G} 3$ & $\mathrm{G} 4$ \\
\hline $\begin{array}{l}\text { Mobile application } \\
\text { Driver }\end{array}$ & $*$ & & & \\
Behavior & & $*$ & & \\
Gamified & & & $*$ & $*$ \\
Gamification & & & & $*$ \\
Driving & & $*$ & & \\
Car & & $*$ & & \\
Vehicle & $*$ & $*$ & & \\
Mobile & & & & \\
Style & & & $*$ & \\
Comportment & $*$ & & & \\
Smartphone & & & & $*$ \\
Engagement & & & & \\
Motivation & & &
\end{tabular}

keywords extracted in the previous step. The extracted data can be exported into JSON and XML format. Specifically, we have used Facundoolano's Google-Play-Scraper [49] and App-Store-Scraper [50] that are both Node.js open-source modules for scraping mobile apps data. In addition, we used the mobile apps repositories to search directly for mobile apps that match the following query: (drive AND safe) OR (drive AND assist) OR (drive AND improve) OR (drive AND behavior) OR (drive AND accident) OR (drive AND behavior AND improve) OR (drive AND behavior AND assist).

3.3.1. Inclusion/Exclusion Criteria. The study included works that met all of the following criteria: works presenting gamified mobile apps that help in the improvement of driving behavior, mobile apps available in the most common digital libraries and mobile apps repositories, and that were published between January 2007 and March 2021. The inclusion and exclusion criteria were applied to the titles and the abstracts or descriptions of identified mobile apps. Only mobile apps that meet the inclusions and exclusions criteria are retained. The inclusion and exclusion for digital libraries are presented in Table 5 and those of mobile apps repositories are presented in Table 6.

3.3.2. Data Extraction. To extract the data from the selected apps, we used the template shown in Table 7. Each data extraction field has a data name, a value, and (if applicable) the associated research question.

\section{Results and Discussion}

In this part, we describe and discuss the extracted data in the form of graphs, diagrams, and tables. First, we present an overview of the selection process, and then the responses to each research question are presented and discussed.

4.1. Overview of Selected Mobile Apps. By searching in selected digital libraries and mobile apps repositories between January 2007 and March 2021, we identified a total of 25229 candidate papers. However, 25150 papers were excluded after applying the exclusion criteria, thus leading to the identification of 79 articles regarding the use of gamification and ML in mobile apps that help in the improvement of driving behavior. Also, we have identified 873 mobile apps in mobile repositories (545 Google Play and 328 Apple Store), but only 92 gamified mobile apps related to driver behavior improvement were selected after the application of inclusion and exclusion criteria.

In digital libraries, 8322 papers were discarded by applying the year filter from January 2007 to March 2021, 16518 papers were rejected according to title and abstract reviewing, 290 papers were rejected after doing a full-text review, and 20 papers were discarded because they are not accessible in full-text. Table 8 presents the number of selected papers after each step of the selection process.

In mobile apps repositories, 83 applications were rejected because they were duplicated. 455 applications were rejected because they are games, driving simulators, or parking simulators. 243 apps were rejected because they were not gamified. Therefore, 49 relevant applications are added manually even if they do not appear in the primary selected applications. Table 9 shows the number of retained mobile apps from mobile apps repositories with the supported operating system.

Among the 105 identified apps in the Play Store, we have found 81 apps that exist also in iOS, and among the 36 identified apps in the App Store, we have found 29 apps that exist also in Android. So, as a final result, we have 110 apps that exist in Android and iOS simultaneously, 24 apps that exist in Android only, and 7 apps that exist in iOS only.

4.2. RQ1: Which Gamified Mobile Apps Related to Driving Behavior Improvement Are Currently Available in the Common Mobile Apps Repositories and Digital Libraries? The goal of RQ1 was to identify mobile apps that improve driving behavior and that are available in the common mobile repositories and digital libraries. A total of 220 apps were identified, and our finding is presented in Table 10 which presents the distribution of selected apps between the years 2007 and 2021.

As illustrated in Table 10, the average annual growth rate of works is $66 \%$ for each year. And the first gamified mobile app helps in improving driver behavior date back to 2009 . The number of mobile apps increased in the following years, with five apps in 2011, 13 apps in 2013, and 25 apps in 2015. However, the numbers dropped to 20 mobile apps in 2016, rising again sharply to peak in 2019 with 49 apps. The numbers dropped again to 13 mobile apps in 2020. Finally, only four apps were developed in the first quarter of 2021. Even considering that the number of works by the first quarter of 2021 is low, the interest in the area appears to have been growing over recent years. Consequently, researchers are becoming more and more interested in this research area.

As we can constate from Tables 8-10, Android presents most of the selected mobile apps related to driver behavior improvement (206 apps) since Android is still dominating 
TABLE 5: Inclusion and exclusion criteria applied in digital libraries.

\begin{tabular}{ll}
\hline Category & Criteria \\
\hline \multirow{5}{*}{ Inclusion } & (i) Works presenting mobile apps that help in the improvement of driving behavior \\
& (ii) Works using gamification as key elements in the design of mobile apps \\
& (iii) Works using machine learning techniques in the development of mobile apps \\
& (iv) Works published between January 2007 and March 2021 \\
& (i) Works not written in English \\
Exclusion & (ii) Works not accessible in full-text \\
& (iii) Books and gray literature \\
& (iv) Duplicate works returned by different search engines \\
& (v) Works consisting of literature reviews or systematic mapping studies
\end{tabular}

TABLE 6: Inclusion and exclusion criteria applied in mobile apps repositories.

\begin{tabular}{ll}
\hline Category & \multicolumn{1}{c}{ Criteria } \\
\hline \multirow{4}{*}{ Inclusion } & (i) Apps presenting mobile apps that help in the improvement of driving behavior \\
& (ii) Apps using gamification as key elements in the design of mobile apps \\
& (iii) Apps using machine learning techniques in the development of mobile apps \\
& (iv) Apps published between January 2007 and March 2021 \\
(i) Duplicate applications \\
(ii) Applications not presented in English \\
(iii) Applications for bikers and cyclists \\
(iv) Games \\
(v) Simulator \\
(vi) Nongamified applications
\end{tabular}

TABLE 7: Data extraction template.

\begin{tabular}{|c|c|c|c|c|}
\hline & Item & Name & Value & RQ \\
\hline \multirow{6}{*}{ App description } & 1 & ID & Integer & - \\
\hline & 2 & Title & Title of the application & RQ1 \\
\hline & 3 & AppId & Identification of the application & RQ1 \\
\hline & 4 & URL & Application URL & RQ1 \\
\hline & 5 & Platform & Mobile operating system & RQ1 \\
\hline & 6 & Released & Application release date & RQ1 \\
\hline \multirow{8}{*}{ App functionalities } & 7 & Multiple languages support & The supported languages by the application & RQ2 \\
\hline & 8 & Authentication & User needs to be authenticated & RQ2 \\
\hline & 9 & Profile creation & The user needs to create his profile & RQ2 \\
\hline & 10 & $\begin{array}{l}\text { Integration with social } \\
\text { networking }\end{array}$ & The user can share score rewards using social networks & RQ2 \\
\hline & 11 & Geolocation & The application collects the driver's location through GPS & RQ2 \\
\hline & 12 & Automatic start & The application can start automatically when detecting driving & RQ2 \\
\hline & 13 & Real-time trip recording & The application records the details of each trip in real-time & RQ2 \\
\hline & 14 & Trip video recording & The application offers the trip video recording in real-time & RQ2 \\
\hline \multirow[t]{3}{*}{ App context } & 15 & Application context & In which context the application was developed & RQ3 \\
\hline & 16 & Data collection phase & When the data are collected, before, during, or after the trip & RQ4 \\
\hline & 17 & Profile data & If the application collects the profile data like age, gender, and address & RQ5 \\
\hline \multirow{4}{*}{$\begin{array}{l}\text { App data } \\
\text { collection }\end{array}$} & 18 & Driving data collection & $\begin{array}{l}\text { If the application needs the driving data like the driver's location and } \\
\text { so on }\end{array}$ & RQ5 \\
\hline & 19 & Driving data collection method & How driving data are collected automatically or manually & RQ5 \\
\hline & 20 & Driver health data collection & If the application collects the driver's health & RQ5 \\
\hline & 21 & Health data collection method & How the health data are collected automatically or manually & RQ5 \\
\hline \multirow{3}{*}{ ML } & 22 & ML algorithms & If the application uses ML algorithms & RQ6 \\
\hline & 23 & ML tasks & Which ML tasks were used by the selected app & RQ6 \\
\hline & 24 & ML algorithms & Which ML algorithms were used by the selected app & RQ6 \\
\hline \multirow{2}{*}{ Gamification } & 25 & Gamified app & If the application is gamified or not & RQ7 \\
\hline & 26 & Gamification elements & Which gamification elements were used by the selected app & RQ7 \\
\hline
\end{tabular}


TABLE 8: The number of retained papers after each step of the selection process.

\begin{tabular}{|c|c|c|c|c|c|c|c|c|c|}
\hline \multirow[b]{2}{*}{$\begin{array}{l}\text { Digital } \\
\text { library }\end{array}$} & \multirow[b]{2}{*}{$\begin{array}{l}\text { Returned } \\
\text { studies }\end{array}$} & \multirow[b]{2}{*}{$\begin{array}{c}\text { Year filter } \\
\text { (2007-March 2021) }\end{array}$} & \multirow[b]{2}{*}{$\begin{array}{l}\text { Title/abstract } \\
\text { review }\end{array}$} & \multirow[b]{2}{*}{$\begin{array}{l}\text { Full-text } \\
\text { review }\end{array}$} & \multicolumn{4}{|c|}{ Retained studies } & \multirow[b]{2}{*}{ Total } \\
\hline & & & & & $\begin{array}{l}\text { Android } \\
\text { only }\end{array}$ & $\begin{array}{l}\text { iOS } \\
\text { only }\end{array}$ & $\begin{array}{c}\text { Android and } \\
\text { iOS }\end{array}$ & $\begin{array}{l}\text { Windows } \\
\text { phone }\end{array}$ & \\
\hline IEEE & 98 & 75 & 19 & 11 & 5 & 0 & 0 & 1 & 6 \\
\hline $\mathrm{ACM}$ & 16243 & 13996 & 236 & 60 & 44 & 3 & 0 & 0 & 47 \\
\hline SCDirect & 456 & 442 & 34 & 10 & 5 & 1 & 2 & 0 & 8 \\
\hline Springer & 8432 & 2394 & 100 & 18 & 15 & 2 & 1 & 0 & 18 \\
\hline Total & 25229 & 16907 & 389 & 99 & 69 & 6 & 3 & 1 & 79 \\
\hline
\end{tabular}

TABLE 9: The number of retained mobile apps from mobile apps repositories with supported OS.

\begin{tabular}{|c|c|c|c|c|c|c|}
\hline $\begin{array}{l}\text { Mobile apps } \\
\text { repositories }\end{array}$ & $\begin{array}{l}\text { Identified } \\
\text { apps }\end{array}$ & $\begin{array}{l}\text { Apps screened for } \\
\text { duplicates }\end{array}$ & $\begin{array}{c}\text { Title/description } \\
\text { review }\end{array}$ & $\begin{array}{c}\text { Apps } \\
\text { screening }\end{array}$ & $\begin{array}{l}\text { Apps added } \\
\text { manually }\end{array}$ & $\begin{array}{l}\text { Selected } \\
\text { apps }\end{array}$ \\
\hline Play Store & 545 & 504 & 269 & Android 71 & Android 34 & 105 \\
\hline App Store & 328 & 286 & 66 & iOS 21 & iOS 15 & 36 \\
\hline Total & 873 & 790 & 335 & 92 & 49 & 141 \\
\hline
\end{tabular}

TABLE 10: Distribution of selected works between 2007 and 2021 .

\begin{tabular}{lcc}
\hline Release year & Apps total number & Apps references \\
\hline 2009 & 1 & {$[51]$} \\
2010 & 1 & {$[52]$} \\
2011 & 5 & {$[53-57]$} \\
2012 & 4 & {$[58-61]$} \\
2013 & 13 & {$[62-74]$} \\
2014 & 8 & {$[75-82]$} \\
2015 & 25 & {$[83-107]$} \\
2016 & 20 & {$[108-127]$} \\
2017 & 33 & {$[128-159]$} \\
2018 & 44 & {$[160-203]$} \\
2019 & 49 & {$[204-252]$} \\
2020 & 13 & {$[253-265]$} \\
2021 & 4 & {$[266-269]$} \\
\hline
\end{tabular}

the market of mobile applications [48]. Figure 2 shows that most of the selected applications are available on both Android and iOS platforms with 113 applications (51\%), while 93 apps (42\%) are available only on Android, 13 applications (6\%) are available only on iOS, and only one application (1\%) is available in the Windows phone operating system. Table 11 presents the evaluation of the hypothesis that we have assumed for research question RQ1.

4.3. RQ2: What Are the Functionalities Offered by These Applications? RQ2 aims to identify the different functionalities offered by the selected applications. As presented in Table 12, the main identified functionalities are geolocation 198 apps (90\%), trip report/driving summary 191 apps (86.81\%), registration and authentication 157 apps (71.36\%), profile creation 148 apps (67.27\%), automatic start (driving mode detection) 68 apps (30.90\%), multiple languages support 67 apps (30.45\%), integration with social networking portals 65 apps (29.54\%), and trip video recording/ event detection 28 apps (12.72\%).

The first most reported functionality is geolocation that is provided by $90 \%$ of selected applications. They use the GPS sensor to provide the user with a range of important services, namely, determining the driving speed and driver guidance, showing the route to a destination, and detecting sudden acceleration, speeding, hard braking, and tight bends [270].

The second most reported functionality is the trip report or trip summary with a percentage of $86.81 \%$, and that is considered as the most important function since it is related to the driving behavior; it collects data about trip start time, end time and duration, GPS latitude and longitude coordinates, and calibrated acceleration and gyroscope measurements [58]. Based on the collected data during each trip, the app will provide score details, which will show the user how he was good at driving. This will allow drivers to understand where threshold violations occurred and possibly identify locations of frequent inappropriate driving and the possibility to post completed trips on their social network profile [58].

The third functionality is registration and authentication that is present in $71.36 \%$ of selected apps. Users can register either by creating an account using Google service or Facebook or creating a new account using an e-mail address. The American Psychiatric Association's app assessment model regarding the use of mobile applications in medical services, privacy, and safety is one of the foundational levels of their framework for mobile app evaluation [271]. Also, privacy and security issues can obstruct users' willingness to share private data, such as real-time locations and contact lists [272]. A survey carried out by Schueller et al. [273] showed that more than $70 \%$ of users of mobile applications in the field of mental health considered that security, privacy, and data encryption are the important keys to be taken into account by mobile apps designers and developers. They affirm that security and privacy are necessary to make users/ patients feel safe to disclose information.

$67.27 \%$ of selected applications invite users to create their profile at registration by asking them for particular information such as age, gender, personal address, and phone number. These pieces of information are useful for classification tasks [274].

Driving mode detection functionality is present in $30.90 \%$ of selected apps. It enables the application to start 


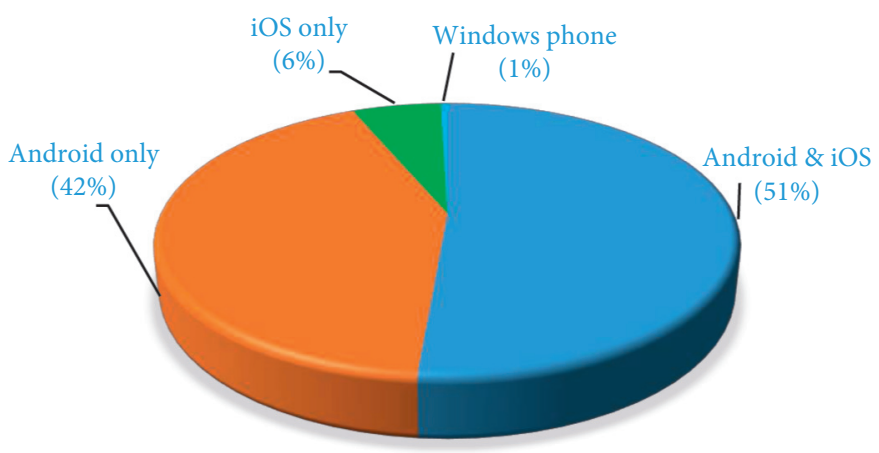

FIGURE 2: Mobile apps OS distribution.

TABLE 11: Evaluation of the hypotheses H1.1 and H1.2

Hypothesis available in the Android platform are more than those available in other platforms.

(H1.2) Several mobile apps for driving behavior improvement are available in many versions for all platforms (Android, iOS, and Windows phone).
As we have identified in Figure 2, most of the selected mobile apps are developed in Android (206 apps). This confirms hypothesis H1.1.

As shown in Figure 2, 51\% of the selected applications are available simultaneously in Android and iOS. Therefore, hypothesis H1.2 is confirmed for Android and iOS. automatically when detecting driving mode such as driving a car, riding a bicycle, riding a bus, walking, and running by using machine learning classifiers [24]. Therefore, the driver does not need to manipulate the smartphone while driving.

$30.45 \%$ of selected applications support more than one language; these applications are available in English and other languages like French, Spanish, German, or Russian while $69.55 \%$ of selected applications are available only in English. Moreover, English remains the most recurrent language supported by the majority of applications because it is considered the most spoken foreign language in the world [275].

Only $29.54 \%$ of selected apps allow the driver to interact with a social network (WhatsApp, Facebook, Twitter, and so on) by posting the completed trips, trip location, time, driven distance, driving score, points, badges, and trophies and sharing it with his/her friends [58].

$12.72 \%$ of selected apps allow the driver to record a video about his trip. Therefore, continuous recording can overcrowd the smartphone memory. For example, DriveSafe app [276] records videos only before and after some event.

To discover patterns about functionalities combinations in the selected mobile apps, we realized the dendrograms presented in Figure 3. The $y$-axis of the diagram represents the similarity order between functionalities according to the Jaccard index (a value in the range $[0,1]$ with 1 : functionalities always used together; 0 : functionalities never used together). One of the most interesting patterns that we discovered was between "profile creation" and "registration and authentication" which were identified together at a level of 0.94 in the first step of the dendrogram (with 148 apps). The second most interesting pattern is discovered between "Geolocation" and "trip report/trip summary" at a level of 0.90 in the second step of the dendrogram (with 184 apps). The third most interesting pattern is a combination between profile creation, registration and authentication, geolocation, and trip report/trip summary; this combination is discovered at a level of 0.71 in the third step of the dendrogram (with 136 apps).

According to these findings, we can conclude that the main functionalities offered by the majority of selected apps are geolocation, trip report/driving summary, registration/ authentication, and profile creation, and these functionalities are the most important in driving behavior improvement apps.

Table 13 presents the evaluation of the hypothesis that we have assumed for the second research question RQ2.

4.4. RQ3: What Data Were Collected and How They Were Collected? The objective of RQ3 is to identify the type of collected data and how these data are collected. As shown in Figure 4, most of the selected mobile apps (55\%) collect driving data which are dynamic data that are collected automatically by the apps using specific sensors like driving speed, traveled distance, the number of hard stops, speeding, slowing down, and sudden acceleration [58, 277]. Also, $40 \%$ of the selected apps collect driver profile data, namely, driver age, gender, and location. Profile data are manually entered by the driver when creating a new account. Both driving and profile data allow to detect driving style and subsequently classify the driver by offering him a score [277] and allow to access detailed driving reports such as hard acceleration events, hard braking, aggressive steering (turns), weaving (lane changes), overspeeding, short car following, driver scoring, and driver behaviors classification [276]. For example, the Amber Driver app [203] offers trip history allowing the driver to access detailed driver reports highlighting indicators such as distance covered, driving behavior, and idle time. 


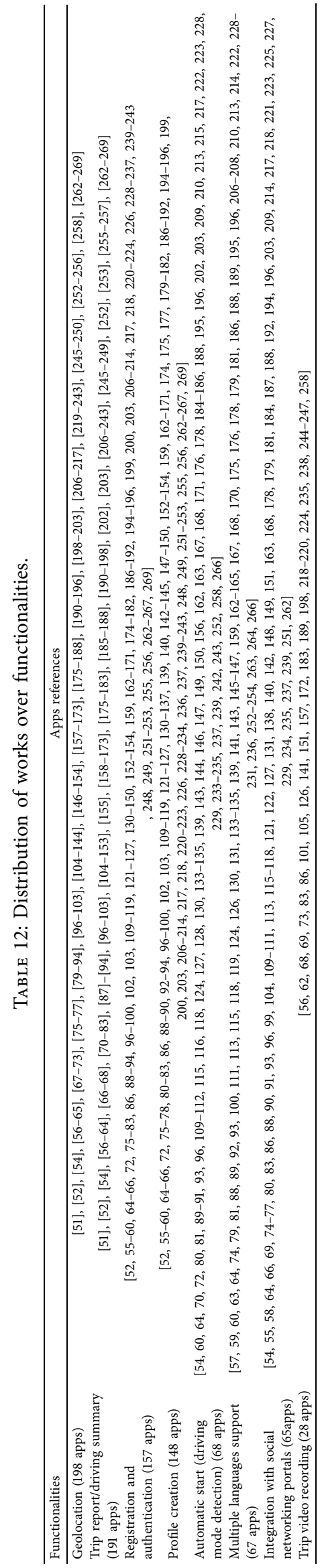




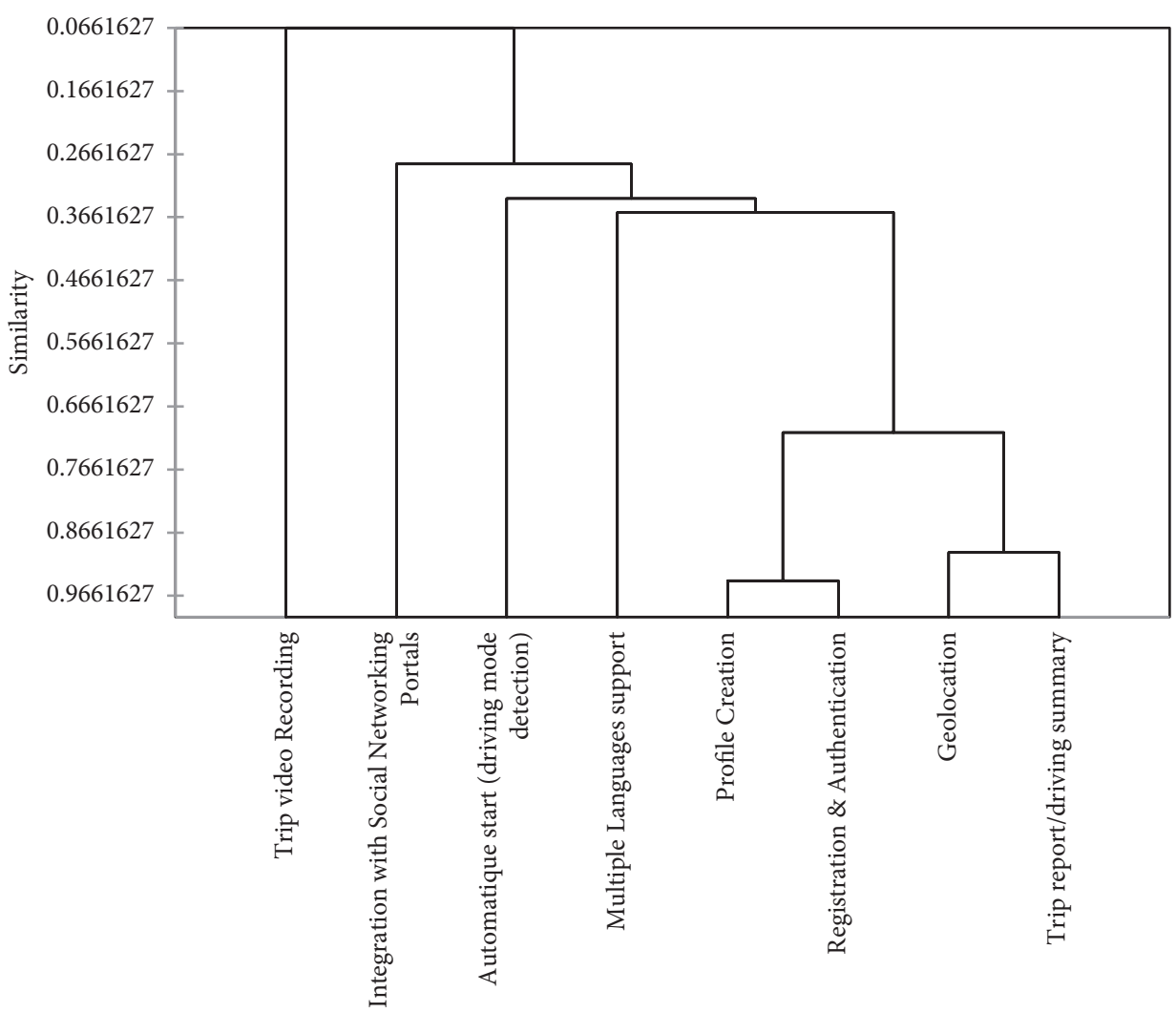

Figure 3: Dendrograms of functionalities coexistence in selected mobile apps.

TABLE 13: Evaluation of the hypothesis H2.

Hypothesis

(H2) There is no significant

difference between the functionalities offered by the selected mobile apps.
Evaluation

As presented above, most of the selected apps provided the main functionalities such as geolocation, trip report/driving summary, registration and authentication, and profile creation. The finding was sufficient to confirm the validity of hypothesis $\mathrm{H} 2$.

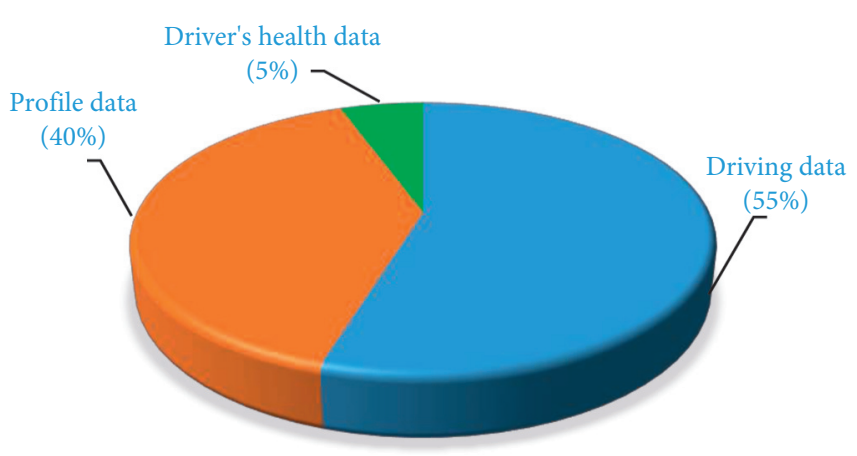

FIgURE 4: Types of collected data.

Unfortunately, a few apps (5\%) collect data about driver's health, such as temperature, heartbeat, detection of fatigue, mood, sobriety, and stress level. For driver's drowsy detection, we have identified six apps, for instance, "Safe Drive" app [259] and "Drowsy Alert: Wake up" app [261] detect driver's drowsiness and distraction during driving using the front camera facing the driver's face and provide audible, textual alerts, and generates relevant context-based recommendations for a driver to avoid possible road accidents. And there are three apps for driver's biological state monitoring; for example, GamECAR platform [249] collects and preprocesses all data related to vehicle and driver status (fuel consumption, gear change, acceleration, braking, and driver's heart rate variability/respiration rate) and extracts informative indicators, such as the eco-score and the aggressiveness score. Three other apps allow driver's stress detection; for example, Sysoev et al. [120] used data such as heart rate variability from chest belt sensor and behavioral and contextual data from smartphones to determine driver's stress level. One app allows the driver's mood recognition [153] by providing a moodbased music recommender system that is capable of regulating the driver's mood and trying to have a positive influence on the driving behavior.

Table 14 presents the evaluation of the hypothesis that we have assumed for research question RQ3.

4.5. RQ4: In Which Phase of Driving the Selected Mobile Apps Took Part? RQ4 aimed to identify the phases when the mobile application took part and when they collect data 
TABLE 14: Evaluation of the hypothesis H4.

Hypothesis

Evaluation

By analyzing the data collected above, we can confirm that most of the selected applications collect driving data or driver profile data. Unfortunately, we have identified a few apps that collect data about driver's health, such as the

(H4) All the selected mobile apps collect data about the driver's profile, context, and health. measurement of driver's temperature and driver's heartbeat and the detection of fatigue, mood, sobriety, and stress level. This finding was sufficient to confirm that hypothesis $\mathrm{H} 4$ is not valid.

about drivers either before driving, during driving, or after driving. As shown in Figure 5, most of the selected apps (214) collect data during driving, but only 5 apps collect data after driving and 4 apps collect data before starting driving.

The analysis of selected apps shows that before driving they collect data that concern just the driver's profile (age, gender, and location). However, before starting to drive, the driver is affected by psychological and physical conditions that affect the quality of driving [278]. Therefore, collecting data that can give information about driver context and conditions before getting behind the wheel is very important and it can reduce considerably driving incidents. For instance, data can concern the quality of sleeping, the effort made before starting to drive, experienced stress, driver irritation, and worry due to a commitment to a meeting or driving under obligation to arrive at a destination at a specific time [278]. Levi-Bliech et al. [21] studied the effects of a fleet management application on driver behavior precisely before driving; the results show that the more drivers use the application before driving, the less likely they are to be involved in driving incidents and subsequently proving good driving. To allow appropriate driving assistance, Bergasa et al. [276] provided a driver condition estimation system that collects information about the driver and provides condition estimation before driving.

As shown in Figure 5, most of the selected applications (210 apps) collect data about drivers while driving. Therefore, several relevant data can be collected like driving speed, traveled distance, number of hard stops, driving style, speeding, slowing down, hard braking, sudden acceleration, and use of the seat belt. The analysis of this kind of data will allow avoiding accidents by alerting the driver in real-time in case of an aggressive driving style [58,277], and it allows the driver to get a detailed report about the trip and assigning a score or a reward using techniques and elements of gamification. In the long term, it will allow the drivers to improve their driving behavior [21, 58].

Collecting data about drivers after driving is also important, it will allow having an evaluation of the effort provided and the stress felt after driving, and also it allows to have an estimate of the fatigue accumulated due to the physical and mental effort provided during the driving $[279,280]$. Ding et al. [279] showed that after finishing driving for more than two hours per day, the drivers were more likely to have various poor physical and mental health outcomes; they showed that longer driving time was associated with higher odds for smoking, insufficient physical activity, short sleep, obesity, and worse physical and mental health. Celis-Morales et al. [280] studied the association between active commuting and incident cardiovascular disease, cancer, and mortality, and they found that those who commuted by car and/or public transport had a higher incidence and mortality from heart disease and cardiovascular disease as compared with those who commuted actively (walking or cycling).

Table 15 presents the evaluation of the hypothesis that we have assumed for research question RQ4.

4.6. RQ5: What Machine Learning Models, Tasks, and Algorithms Are Used to Analyze the Collected Data? RQ5 aims to determine the ML models, tasks, and algorithms used for the analysis of the collected data. For the selected mobile apps from digital libraries, all information's about ML models, tasks, and techniques are available in the related papers. However, for the selected mobile apps from mobile repositories, firstly, we examine the descriptions of each selected mobile app; secondly, we consult the developer's websites for recovering information about the use of machine learning algorithms in their apps, and eventually, we contacted the mobile apps developers and we ask them about the use of machine learning in their applications.

Among the 220 selected applications, 99 apps (45\%) use machine learning algorithms. Usually, machine learning algorithms are used for the scoring of driving style, for the adaptation of the application to the context and the profile of the driver, to determine his behavior on the road or to stop the vehicle remotely in case of inappropriate behavior.

As shown in Table 16, among the 99 selected applications that use machine learning algorithms, 89.13\% (41 apps) used the supervised learning model, $8.70 \%$ used the unsupervised learning model (4 apps), and only $2.17 \%$ (1 app) combined the supervised and unsupervised learning model. Also, among the selected applications that use machine learning algorithms, $84.79 \%$ (39 apps) applied classification tasks, $6.52 \%$ (3 apps) applied clustering tasks, also $4.35 \%$ (2 apps) applied regression tasks, $2.17 \%$ (1 app) combined classification and clustering tasks, and $2.17 \%$ (1 app) applied dimension reduction tasks. Also, we have identified 7 techniques that are the most used in the selected mobile apps: neural networks (NNs) with $38.30 \%$, support vector machines (SVMs) with $23.40 \%$, decision tree (DT) with $19.15 \%$, k-means with $6.38 \%$, Bayesian learners (BL) with $4.26 \%$, and finally binary logistic regression (BLR), support vector regression (SVR), expectation maximization (EM), and independent 


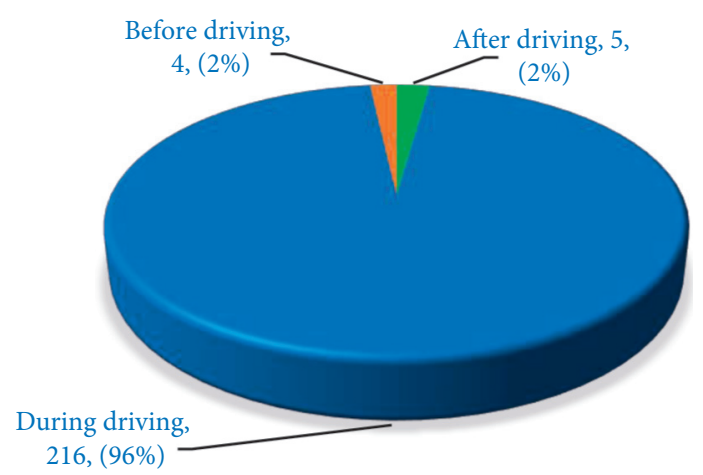

Figure 5: Data collection phases.

component analysis (ICA) technique with $2.13 \%$ for each of them.

Table 17 shows the usage of the ML technique in the identified apps, for example, support vector machine (SVM) is used for driver's sobriety evaluation to avoid driving under the influence of alcohol [197], and also SVM is used for driver's stress detection [244, 247] and driver's drowsy detection $[62,257]$. The neural network $(\mathrm{NN})$ technique is used for driver's drowsy detection [204] and driver's drowsy and fatigue detection [101]. K-means technique is used to separate aggressive from nonaggressive trips, to distinguish "normal" trips from unsafe trips [242]. Decision tree (DT) technique is used for driver's stress detection [120], and independent component analysis (ICA) technique is used for driver's biological state monitoring [85].

Table 18 presents the evaluation of the hypothesis that we have assumed for research question RQ5.

4.7. RQ6: What Are the Gamification Elements Used by Selected Applications? The goal of RQ6 was to understand how gamification was implemented in driving enhancement applications. Thus, we collected data on the different gamification elements used in the selected mobile apps. To have a standard terminology of gamification elements used in selected mobile apps, we have used results obtained by previous research work in the categorization of gamification elements. Mainly, we have used the taxonomy proposed by Cheng et al. [281] and Tondello et al. [282].

Table 19 shows the distribution of the selected applications according to the gamification elements identified in each application. Therefore, a total of 6 gamification elements were identified in the 220 selected mobile apps.

As shown in Table 19, the selected mobile apps have mainly used the following element: "Levels or progress feedback" was used in 167 apps (75.91\%), followed by "Points or scoring" that was used in 150 apps (68.18\%), then "Socialization" that was identified in 86 apps (39.09\%), also 43 apps used "Rewards or prizes" with a percentage of $19.55 \%, 36$ apps used "Badges or achievements" with $16.36 \%$, and finally "Customization" was used in 30 apps $(13.64 \%)$.

According to Tondello et al. [282], "Levels or progress feedback" elements can be presented in the form of a level and progression bar. The level element is generally used to show the level of experience. This is a good solution for creating a constant feeling of progression. For each level, a set of tasks are defined to be accomplished and users go from one level to another as they accomplish tasks and reach a certain number of points [10, 283-285]. For example, SAFE.T Prevention app [232] offers multiple levels with increasing complexity. The intention here is that drivers strive to achieve the highest possible level. Also, a lot of applications use the "progress feedback" to keep the drivers informed of their progress or failures in real-time via leaderboards, messages, or other visual/audio or informative displays [10]. Axo Driver app [162] visualizes briefly the axes of progression per journey. Raptis et al. [193] proposed a mobile application that provides drivers with feedback during and after their drive; ML algorithms are used to make drivers aware of potentially dangerous practices on how they hold the steering wheel. DriveSafe [286] is an example of mobile apps that improves driving by obtaining feedback on driver behavior. DrivActiv iSight app [262] is another example of mobile apps that sends to the drivers real-time feedback that reinforces positive driving attributes and addresses poor behaviors.

Almost all applications use the "Points or scoring" elements to assess the driving style and behavior on the road, and also a driving score is used to give feedback to the driver so that the driver can analyze his driving habits [287]. For example, DriveSafe app [73] scores each trip according to seven maneuvers: accelerations, brakings, turnings, laneweaving, lane-drifting, overspeeding, and car-following. It also rates each trip within three behavior models: normal, drowsy, and aggressive. However, the DriveSafe app [176] scores each trip using an advanced scoring model of drive safe which takes into consideration driving over the speed limit, using the mobile phone whilst driving, braking (sudden and aggressive braking), acceleration (sharp and aggressive acceleration), and driving during the most dangerous hours (00:00-05:00).

According to Tondello et al. [282], "Socialization" elements can be presented in the form of a challenge, leaderboard, or social interaction. The challenge component that is considered as a kind of competition between two users or between teams allows users to compete against each other [284]. For instance, the Drive Master app [110] rewards the driver with CapitaVouchers and more when the driver refers friends or wins periodic challenges, and the driver can invite his friends for a challenge and see who is leading the leaderboard. SAFE.T Prevention app [232] uses a challenge component for motivating drivers to improve their skills. The leaderboard allows viewing user progress and relative success against adversaries $[10,285]$. This element uses the basic idea, that people want to be the best, to be at the top of the rankings. For instance, Leaderboard was used in GreenRoad Drive app [59] where each driver is assigned a safety score reflecting the frequency of their safety events. Drivers are motivated to improve their safety scores and team rankings. Social interaction and relationships [283] include the range of interactions that lead to emotional dimensions like camaraderie and social networking relationships that allow players to interact with others. For 
TABLE 15: Evaluation of the hypothesis H5.

\begin{tabular}{lc}
\hline Hypothesis & Evaluation \\
\hline $\begin{array}{ll}\text { (H5) All the selected mobile apps collect data about } \\
\text { drivers before, during, and after driving. }\end{array}$ & Most of the selected applications (210 apps) collect data about drivers while \\
driving. The finding was sufficient to confirm that hypothesis H5 is not valid.
\end{tabular}

TABLE 16: ML models, tasks, and technique of the selected apps.

\begin{tabular}{|c|c|c|c|c|c|}
\hline ML model & Frequency & ML task & Frequency & ML technique & Frequency \\
\hline \multirow{6}{*}{ Supervised learning } & \multirow{6}{*}{42} & \multirow{4}{*}{ Classification } & \multirow{4}{*}{40} & Neural networks (NNs) & 18 \\
\hline & & & & Support vector machines (SVMs) & 11 \\
\hline & & & & Decision tree $(\mathrm{DT})$ & 9 \\
\hline & & & & Bayesian learners (BL) & 2 \\
\hline & & & & Binary logistic regression (BLR) & 1 \\
\hline & & Regression & 2 & Support vector regression (SVR) & 1 \\
\hline \multirow{3}{*}{ Unsupervised learning } & \multirow{3}{*}{5} & Clustering & 4 & K-means & 3 \\
\hline & & Clusterıng & 4 & Expectation maximization (EM) & 1 \\
\hline & & Dimension reduction & 1 & ICA & 1 \\
\hline
\end{tabular}

TABLE 17: Usage of ML techniques in the identified works.

\begin{tabular}{lc}
\hline ML technique & Apps references \\
\hline Neural networks (NNs) & {$[80,93,101,126,141,156,179,183,189,204,220,221,225,229,235,238,250,254]$} \\
Support vector machines (SVMs) & {$[62,87,173,193,197,198,201,244,247,256,257]$} \\
Decision tree (DT) & {$[71,73,103,120,177,200,252,269]$} \\
K-means & {$[109,242]$} \\
Expectation maximization (EM) & {$[153]$} \\
Bayesian learners (BL) & {$[82,245]$} \\
Binary logistic regression (BLR) & {$[243]$} \\
Support vector regression (SVR) & {$[246]$} \\
DT and CL & {$[84]$} \\
Independent component analysis (ICA) & {$[85]$} \\
\hline
\end{tabular}

TABLE 18: Evaluation of the hypothesis H5.

\begin{tabular}{lc}
\hline Hypothesis & Evaluation \\
\hline $\begin{array}{l}\text { (H5) Classification is the most used ML task in } \\
\text { driving behavior analysis. }\end{array}$ & $\begin{array}{l}\text { Results showed that among the selected applications that use machine learning } \\
\text { algorithms, most apps applied classification tasks and few apps applied other tasks. } \\
\text { This finding was sufficient to confirm hypothesis H6. }\end{array}$ \\
\hline
\end{tabular}

instance, an application such as AI Smart Driving app [221] allows sharing driving scores and driving certificates in social media with friends and family members to let them know the driving skills of other drivers.

"Rewards or prizes" elements are considered as a way of recognition of users' efforts in the accomplishment of some tasks [46, 288]; rewards can be presented in the form of a service discount, gifts, or monetary. Discount as a kind of extrinsic reward motivates users to improve their engagement by benefiting from a discount on certain services. It is demonstrated that if these rewards are removed, users will disengage [289]. This is the case for applications developed in collaboration with insurance companies [58]. For instance, the Drive Safe app [176] suggests to their customers to participate in a driver behavior program, and the participants may get a better insurance rate (Insurance discount) according to their driving behavior. Other apps allow the drivers with a good driving score to earn a daily reward voucher redeemable on Amazon or the App Store and
iTunes. Gifts allow users to enjoy the benefits of freebies, help, and altruism. And the sharing of resources between users [283], for example, AVIS SafeDrive app [139], allows users how to get a higher driving score to earn a daily reward voucher redeemable at Amazon or iTunes for good driving. The Betterways app [127] sets automatic rewards for the best behaving drivers in the fleet, and the company sends out the gift cards for the driver. With the GreenRoad Drive app [59], the managers can award their best drivers with redeemable gifts, delivered directly within the mobile app (e.g., coffee shop gift cards). The money reward element is considered as an extrinsic motivation in which the user performs activities to get a tangible reward [46]. For instance, the OnMyWay app [217] pays its users who do not use messaging while driving, and the money earned can then be used for cash cards, gift cards, and travel deals.

Badges are given to users to give them something that can prove their driving skills. They have the same principle of medals, and they can be earned permanently or just for a short 


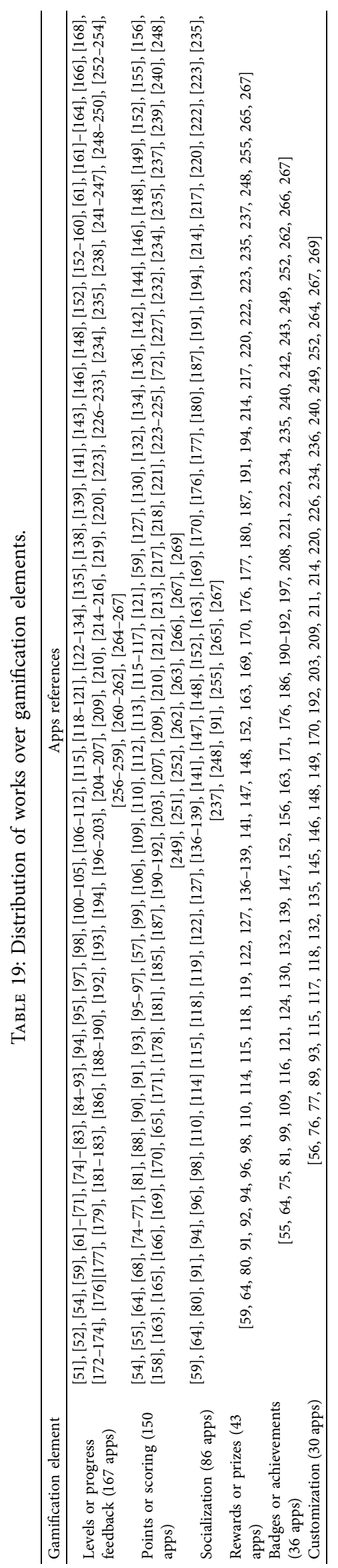




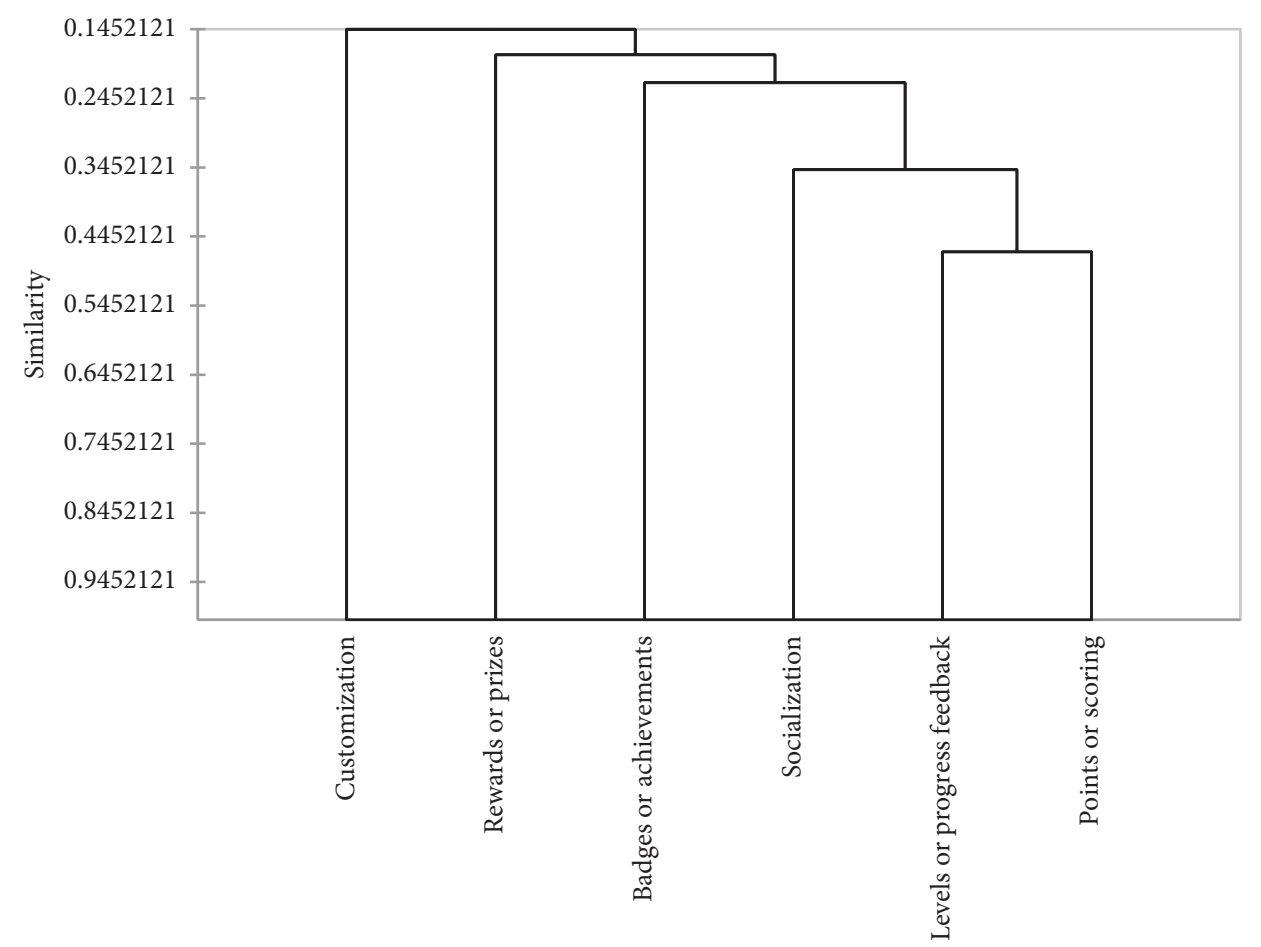

Figure 6: Dendrograms of patterns of how often gamification elements are used together.

period. The available badges are usually known in advance to motivate the user to achieve personal goals without direct competition [290]. For instance, the CoPiloTT app [163] allows earning virtual badges and points that could be redeemed to real goodies. Achievements reward users for achieving a clear and desirable goal, and they also can be defined as the accomplishment of activities over a certain period or the accumulation of a certain number of reward elements [10, 283, 290]. For example, the DrivActiv iSight app [262] monitors a driver's performance behind the wheel, identifies areas of improvement, offers suggestions, and rewards good drivers with safe driving certificates. Also, the Safest Driver ${ }^{\mathrm{TM}}$ app [234] allows the driver to collect stars for safe driving.

According to Tondello et al. [282], the "Customization" element can be presented as the avatar/picture component. It is the way by which users choose to express themselves to other members of the community [285]. This is a graphical representation of the user in the game. For example, the SAFE 2 SAVE app [115] allows the user to personalize his profile and stand out in the drivers community.

To discover patterns about gamification element combinations in the selected mobile apps, we realized the dendrograms presented in Figure 6. The $y$-axis of the diagram represents the similarity order between gamification elements according to the Jaccard index (a value in the range $[0,1]$ with 1: gamification elements always used together; 0 : gamification elements never used together).

As shown in Figure 6, the first most interesting patterns that we found were between "Points or scoring" and "Levels or progress feedback" that are the most used together in selected mobile apps at a level of 0.47 . This would appear to make sense as the "Levels or progress feedback" elements offer a visualization allowing the user to check and follow his/her progress (earned Points or scoring) in an activity using a dashboard [283]. The second pattern is discovered between the merged pair "Points or scoring" with "Levels or progress feedback" and Socialization elements at a level of 0.35 in the second step of the dendrogram. This would appear to make sense as the driver uses the Socialization element (leaderboard, challenges/competition, and social interaction) to share with his/her friends the completed trip report, driving points, scoring, progression, and attained level [58].

According to these findings, we can conclude that the 3 main gamification elements offered by the majority of driver behavior improvement apps are "Points or scoring," "Levels or progress feedback," and Socialization elements. These elements allow promoting the active interest of drivers and their engagement to improve their behaviors. Developers may consider these findings to build a more compelling app for driver behavior improvement.

Table 20 presents the evaluation of the hypothesis that we have assumed for research question RQ6.

\section{Limitations of the Study}

Concerning the research methods, some limitations need to be acknowledged. Firstly, PICO criteria were used in the development of the research string to identify applications that help improve driver behavior, but the term "gamification" is excluded from the research string to not have games like apps in the search result. Secondly, even though the selected apps were chosen by reviewing and studying their titles, description, screenshots, and videos, other 
TABLE 20: Evaluation of the hypothesis H6.1 and H6.2

Hypothesis
(H6.1) There is no significant difference between the use of
gamification elements in selected mobile apps.

(H6.2) All the selected mobile apps use a combination of several gamification elements to ensure driver engagement and motivation.

relevant apps might have been missed. Finally, despite the variety of methods used to extract information on whether or not to use machine learning algorithms to develop these selected applications, some applications do not reveal the method used in their development.

\section{Conclusion and Future Work}

Despite the efforts of several countries, organizations, and companies to take measures and actions for road safety, road accidents remain the main cause of death over the world. This implies the importance of educating drivers about safe driving. One of the ingenious ways to educate and empower drivers is to harness mobile technologies in driver assistance and in reducing crash rates and preventing accidents; this is made mainly by the use of mobile apps that help in improving driver behavior. Machine learning can make these applications smarter and more adaptable to contexts and driver profiles. And with the help of gamification elements, drivers will be more responsible and will respect more strictly the rules of the road.

In this article, we investigated the state of the synergy of mobile technologies, machine learning, and gamification in the design and development of mobile apps for improving driver behavior on the road. The work is presented in the form of a systematic mapping study, in which we have studied the provided functionalities and services of 220 selected gamified mobile applications that help in improving driving behavior.

The results of this study indicate that the most interesting functionalities in the selected mobile apps are geolocation, trip report/driving summary, registration/authentication, and profile creation. Also, to promote the active interest of drivers and their engagement in the improvement of their behavior, the selected mobile apps use gamification elements as "Levels or progress feedback" elements, "Points or scoring" elements, "Socialization elements," "Rewards or prizes" element, "Badges or achievements" elements, and "Customization" elements. In general, these gamification elements have been implemented in several contexts and have been combined in various ways by the developers to provide promote the motivation and the engagement of drivers. Mainly, we have discovered the relevance of
Evaluation

Results showed that the majority of the studied apps used "Points or scoring," "Levels or progress feedback," and Socialization element as principal gamification elements in the design of a gamified mobile app for driving behavior improvement. This finding was sufficient to confirm the validity of hypothesis H6.1.

As shown in Figure 6 and as described above, several gamification elements were used together in many mobile apps. This finding was sufficient to confirm the validity of hypothesis H6.2.

combining "Points or scoring," "Levels or progress feedback," and "Socialization" elements.

Most of the selected applications collect driving data (e.g., driving speed, traveled distance, the number of hard stops, speeding, slowing down, and sudden acceleration) or driver profile data (e.g., driver age, gender, and location). Unfortunately, only a few apps collect data about driver's health, such as the collection of temperature and driver heartbeat, detection of fatigue, mood, sobriety, and stress level. Also, results showed that before driving, the selected apps collect data that concern just the driver's profile (age, gender, and location). However, before starting to drive, the driver is affected by psychological and physical condition factors that can affect the quality of driving (quality of sleeping, the effort made before starting to drive, experienced stress, driver irritation, worry due to a commitment to a meeting or driving under obligation to arrive at a destination at a specific time, and so on). On the other hand, most of the selected applications collect data about drivers while driving, like driving speed, traveled distance, number of hard stops, driving style, speeding, slowing down, hard braking, sudden acceleration, and use of the seat belt. Finally, despite the importance of driving experience feedback in the evaluations of drivers' physical and/or mental state after driving, only one app collects driver's health data (anxiety) before and after driving by manually filling out a short STAI questionnaire to assess personal anxiety and anxiety as a state at a certain moment.

The analysis of 220 apps revealed that 99 apps have used machine learning algorithms. Generally, machine learning algorithms are used for the scoring of driving style, for the adaptation of the application to the context and profile of the driver, to determine the driver behavior on the road, and to stop the vehicle remotely in case of inappropriate behavior. We found that the majority of selected apps used a supervised learning model, and a few of them used an unsupervised learning model, and only one app combined a supervised and unsupervised model. Finally, among the selected applications that use machine learning, we found that most of them apply classification tasks; on the other hand, a few apps apply clustering or regression tasks. Moreover, we have found that the most used machine learning techniques were neural networks (NNs) followed by 
the support vector machine (SVM) technique and then the decision tree (DT) technique, clustering (CL) technique, Bayesian learners (BL), and regression (RE) techniques.

Our future studies will be consecrated to the realization of a systematic literature review (SLR) that will make an indepth analysis of all studies published recently on the topic of the use of machine learning algorithms and gamification elements in the design and development of mobile apps for driving behavior improvement.

\section{Data Availability}

The data used to support this study are available on request by sending an e-mail to taoufik.rachad@um5.ac.ma.

\section{Conflicts of Interest}

The authors declare that they have no conflicts of interest.

\section{References}

[1] C. Pélissier, E. Fort, L. Fontana, and M. Hours, "Medical and socio-occupational predictive factors of psychological distress 5 years after a road accident: a prospective study," Social Psychiatry and Psychiatric Epidemiology, vol. 55, no. 3, pp. 371-383, 2020.

[2] World Health Organization, Global Status Report on Road Safety 2018, World Health Organization, vol. 10, no. 2, Geneva, Switzerland, 2018.

[3] P. Muhlethaler, "Exploring the forecasting approach for road accidents: analytical measures," Expert Systems with Applications, vol. 167, Article ID 113855, 2020.

[4] Q. Lequeux and J. Leblud, "Rapport statistique 2018: accidents de la route 2017 (DRAFT), no. D/2018/0779/85," 2019.

[5] L. Eboli, C. Forciniti, and G. Mazzulla, "Factors influencing accident severity: an analysis by road accident type," Transportation Research Procedia, vol. 47, pp. 449-456, 2020.

[6] T. K. Chan, C. S. Chin, H. Chen, and X. Zhong, "A comprehensive review of driver behavior analysis utilizing smartphones," IEEE Transactions on Intelligent Transportation Systems, vol. 21, no. 10, pp. 4444-4475, 2019.

[7] H. S. Kim, Y. Hwang, D. Yoon, W. Choi, and C. H. Park, "Driver workload characteristics analysis using EEG data from an urban road," IEEE Transactions on Intelligent Transportation Systems, vol. 15, no. 4, pp. 1844-1849, 2014.

[8] C. Charbit, "Les facteurs humains dans les accidents de la circulation: un potentiel important pour des actions de prévention," 1997.

[9] S. Phithakkitnukoon and R. Shibasaki, "Challenges of human behavior understanding," 2010.

[10] S. Thiebes, S. Lins, and D. Basten, "Gamifying information systems-a synthesis of gamification mechanics and dynamics," 2014.

[11] C. Diane, "What is a 'mapping study?'," Journal of the Medical Library Association, vol. 104, no. 1, pp. 76-78, 2016.

[12] M. Amarasinghe, S. Kottegoda, A. L. Arachchi, S. Muramudalige, H. M. N. Dilum Bandara, and A. Azeez, "Cloud-based driver monitoring and vehicle diagnostic with OBD2 telematics," in Proceedings of the 2015 IEEE International Conference on Electro/Information Technology (EIT), pp. 505-510, Dekalb, IL, USA, May 2015.

[13] B. Nirmali, S. Wickramasinghe, T. Munasinghe, C. R. J. Amalraj, and H. M. N. D. Bandara, "Vehicular data acquisition and analytics system for real-time driver behavior monitoring and anomaly detection," in Proceedings of the 2017 IEEE International Conference on Industrial and Information Systems (ICIIS), pp. 1-6, Peradeniya, Sri Lanka, January 2018.

[14] H. Cao and M. Wachowicz, "A holistic overview of anticipatory learning for the internet of moving things: research challenges and opportunities," ISPRS International Journal of Geo-Information, vol. 9, no. 4, 2020.

[15] A. I. Dumitru, T. Girbacia, R. G. Boboc, C.-C. Postelnicu, and G.-L. Mogan, "Effects of smartphone based advanced driver assistance system on distracted driving behavior: a simulator study," Computers in Human Behavior, vol. 83, pp. 1-7, 2018.

[16] A. Ziebinski, R. Cupek, D. Grzechca, and L. Chruszczyk, "Review of advanced driver assistance systems (ADAS)," AIP Conference Proceedings, vol. 1906, 2017.

[17] A. Ziebinski, R. Cupek, H. Erdogan, and S. Waechter, “A survey of ADAS technologies for the future perspective of sensor fusion," Computational Collective Intelligence, vol. 2, pp. 135-146, 2016.

[18] N. Benlagha and L. Charfeddine, "Risk factors of road accident severity and the development of a new system for prevention: new insights from China," Accident Analysis \& Prevention, vol. 136, Article ID 105411, 2020.

[19] C. Brooks and A. Rakotonirainy, "In-vehicle technologies, advanced driver assistance systems and driver distraction: research challenges," in Proceedings of the International Conference on Distracted Driving, pp. 471-486, Sydney, Australia, June 2005.

[20] R. Chhabra, C. R. Krishna, and S. Verma, "Smartphone based context-aware driver behavior classification using dynamic Bayesian network," Journal of Intelligent and Fuzzy Systems, vol. 36, no. 5, pp. 4399-4412, 2019.

[21] M. Levi-Bliech, P. Kurtser, N. Pliskin, and L. Fink, "The effects of a fleet-management app on driver behavior," in Proceedings of the 26th European Conference on Information Systems: Beyond Digitization-Facets of Socio-Technical Change, ECIS 2018, Portsmouth, UK, June 2018.

[22] K. Bylykbashi, E. Qafzezi, M. Ikeda, K. Matsuo, and L. Barolli, "Fuzzy-based driver monitoring system (FDMS): implementation of two intelligent FDMSs and a testbed for safe driving in VANETs," Future Generation Computer Systems, vol. 105, pp. 665-674, 2020.

[23] T. Rachad and A. Idri, "Intelligent mobile applications: a systematic mapping study," Mobile Information Systems, vol. 2020, Article ID 6715363, 17 pages, 2020.

[24] A. Jahangiri and H. A. Rakha, "Applying machine learning techniques to transportation mode recognition using mobile phone sensor data," IEEE Transactions on Intelligent Transportation Systems, vol. 16, no. 5, pp. 2406-2417, 2015.

[25] J. Ferreira, E. Carvalho, B. V. Ferreira et al., "Driver behavior profiling: an investigation with different smartphone sensors and machine learning," PLoS One, vol. 12, no. 4, Article ID e0174959, 2017.

[26] H. Eren, S. Makinist, E. Akin, and A. Yilmaz, "Estimating driving behavior by a smartphone," in Proceedings of the 2016 IEEE Intelligent Vehicles Symposium, pp. 234-239, Gotenburg, Sweden, March 2016.

[27] C. Jacobé de Naurois, C. Bourdin, A. Stratulat, E. Diaz, and J.-L. Vercher, "Detection and prediction of driver drowsiness using artificial neural network models," Accident Analysis \& Prevention, vol. 126, pp. 95-104, 2019. 
[28] R. Chhabra, S. Verma, and R. Krishna, "A survey on driver behavior detection techniques for intelligent transportation systems," in Proceedings of the 7th International Conference Confluence 2017 on Cloud Computing, Data Science and Engineering, vol. 7, pp. 36-41, Noida, India, January 2017.

[29] P. Ping, W. Qin, Y. Xu, C. Miyajima, and K. Takeda, "Impact of driver behavior on fuel consumption: classification, evaluation and prediction using machine learning," IEEE Access, vol. 7, pp. 78515-78532, 2019.

[30] R. C. Shit, "Crowd intelligence for sustainable futuristic intelligent transportation system: a review," IET Intelligent Transport Systems, vol. 14, no. 6, pp. 480-494, 2020.

[31] A. Kashevnik, I. Lashkov, and N. Teslya, "Driver intelligent support system in internet of transportation things: smartphone-based approach," in Proceedings of the 2019 14th Annual Conference System of Systems Engineering (SoSE), pp. 170-175, Anchorage, AK, USA, May 2019.

[32] S. Deterding, K. O'Hara, M. Sicart, D. Dixon, and L. Nacke, "Gamification: using game design elements in non-gaming contexts," in Proceedings of the Conference on Human Factors in Computing Systems, pp. 2425-2428, Vancouver, BC, Canada, May 2014.

[33] S. Deterding and D. Dixon, "From game design elements to gamefulness: defining gamification," in Proceedings of the 15th International Academic MindTrek Conference: Envisioning Future Media Environments, Tampere, Finland, September 2011.

[34] S. Deterding, D. Dixon, R. Khaled, and L. Nacke, "Gamification: toward a definition," in Proceedings of the CHI 2011 Gamification Work, pp. 12-15, Vancouver, BC, Canada, January 2011.

[35] K. Werbach, "(Re)Defining gamification: a process approach gamification as a process," in Proceedings of the International Conference on Persuasive Technology, pp. 266-272, Padua, Italy, May 2014.

[36] E. Mantouka, E. Barmpounakis, E. Vlahogianni, and J. Golias, "Smartphone sensing for understanding driving behavior: current practice and challenges," International Journal of Transportation Science and Technology, 2020, In press.

[37] V. C. Magaña and M. M. Organero, "The impact of using gamification on the eco-driving learning," pp. 241-252, 2014.

[38] S. Wells, H. Kotkanen, M. Schlafli et al., "Towards an applied gamification model for tracking, managing, \& encouraging sustainable travel behaviours," ICST Transactions on Ambient Systems, vol. 1, no. 4, p. e2, 2014.

[39] Z. Fitz-Walter, D. Johnson, P. Wyeth, D. Tjondronegoro, and B. Scott-Parker, "Driven to drive? Investigating the effect of gamification on learner driver behavior, perceived motivation and user experience," Computers in Human Behavior, vol. 71, pp. 586-595, 2017.

[40] S. Diewald, A. Möller, L. Roalter, T. Stockinger, and M. Kranz, "Gameful design in the automotive domain review, outlook and challenges," in Proceedings of the International Conference on Automotive User Interfaces and. Interactive Vehicular Applications (AutomotiveUI 2013), pp. 262-265, Eindhoven, Netherlands, October 2013.

[41] P. Runeson and M. Höst, "Tutorial: case studies in software engineering," Lecture Notes in Business Information Processing, Springer, vol. 32, pp. 441-442, , Berlin, Germany, 2009.

[42] K. Petersen, S. Vakkalanka, and L. Kuzniarz, "Guidelines for conducting systematic mapping studies in software engineering: an update," Information and Software Technology, vol. 64, pp. 1-18, 2015.

[43] K. Petersen, R. Feldt, S. Mujtaba, and M. Mattsson, "Systematic mapping studies in software engineering," in Proceedings of the 12th international conference on Evaluation and Assessment in Software Engineering (EASE 2008), Durham, UK, June 2008.

[44] B. Dignen, Systematic Reviews CRD's Guidance for Undertaking Reviews in Health care, York Associates, Granville, OH, USA, 1394.

[45] P. W. Stone, "Popping the (PICO) question in research and evidence-based practice," Applied Nursing Research, vol. 15, no. 3, pp. 197-198, 2002.

[46] A. Tlili and M. Chang, "Data analytics approaches in educational games and gamification systems: summary, challenges, and future insights," 2019.

[47] H. Zhang, M. A. Babar, and P. Tell, "Identifying relevant studies in software engineering," Information and Software Technology, vol. 53, no. 6, pp. 625-637, 2011.

[48] IDC-Smartphone Market Share-OS, https://www.idc.com/ promo/smartphone-market-share.

[49] GitHub-facundoolano/google-play-scraper: Node.js scraper to get data from Google Play, 2020, https://github.com/ facundoolano/google-play-scraper.

[50] GitHub-facundoolano/app-store-scraper: scrape data from the itunes app store, 2020, https://github.com/facundoolano/ app-store-scraper.

[51] A. Riener, A. Ferscha, and M. Aly, "Heart on the road: HRV analysis for monitoring a driver's affective state," in Proceedings of the First International Conference on. Automotive User Interfaces and Interactive. Vehicular Applications (AutomotiveUI), pp. 99-106, Essen, Germany, September 2009.

[52] iDriveSafe, 2021, http://sisinflab.poliba.it/swottools/ idrivesafe/.

[53] A. S. M. Mahfujur Rahman, J. Saboune, and A. El Saddik, "Motion-path based in car gesture control of the multimedia devices," in Proceedings of the First ACM International Symposium on Design and Analysis of Intelligent Vehicular Networks and Applications (DIVANet'11), pp. 69-75, Miami, FL, USA, November 2011.

[54] R. Ecker, P. Holzer, V. Broy, and A. Butz, "EcoChallenge: a race for efficiency," in Proceedings of the 13th International Conference on Human Computer Interaction with Mobile Devices and Services (MobileHCI '11), pp. 91-94, Stockholm, Sweden, August 2011.

[55] F. L. Law, Z. M. Kasirun, and C. K. Gan, "Gamification towards sustainable mobile application," in Proceedings of the 2011 Malaysian Conference in Software Engineering, 2011, Mobile computing, International Conference on Measurement and Control Engineering 2nd (ICMCE 2011), pp. 349-353, Kuantan, Pahang, Malaysia, June 2011.

[56] iOnRoad, 2021, https://apkpure.com/ionroad-augmenteddriving-lite/com.picitup.iOnRoad.

[57] ABAX Driver, 2021, https://play.google.com/store/apps/ details?id=no.ets.client.j2me.ETSClient.

[58] J. Paefgen, F. Kehr, Y. Zhai, and F. Michahelles, "Driving behavior analysis with smartphones: insights from a controlled field study," in Proceedings of the 11th International Conference on Mobile and Ubiquitous Multimedia, Ulm, Germany, December 2012.

[59] GreenRoad Drive, 2021, https://play.google.com/store/apps/ details?id=com.greenroad.mobile.drive. 
[60] Saving Fuel, 2021, https://play.google.com/store/apps/ details?id=savingfuel.obd2.

[61] J. Tulusan, T. Staake, and E. Fleisch, "Providing eco-driving feedback to corporate car drivers: what impact does a smartphone application have on their fuel efficiency?" in Proceedings of the 2012 ACM Conference on Ubiquitous Computing-UbiComp '12, p. 212, Pittsburgh, PA, USA, September 2012.

[62] C. W. You, L. Torresani, A. T. Campbell et al., "CarSafe app: alerting drowsy and distracted drivers using dual cameras on smartphones," in Proceedings of the Eleventh International Conference on Mobile Systems, Applications, and Services (MobiSys 2013), pp. 461-462, Seoul, South Korea, October 2013.

[63] M. Kracheel, R. McCall, V. Koenig, and T. Engel, "Driver diaries: a multimodal mobility behaviour logging methodology," in Proceedings of the 5th International Conference on Automotive User Interfaces and Interactive Vehicular Applications, Automotive 2013, pp. 254-257, Eindhoven, Netherlands, October 2013.

[64] DriveWell, 2021, https://play.google.com/store/apps/details? id $=$ com.cmtelematics.drivewell.

[65] C. Tanas and J. Herrera-Joancomartí, "Users as smart sensors: a mobile platform for sensing public transport incidents," in Lecture Notes in Computer Science (including subseries Lecture Notes in Artificial Intelligence and Lecture Notes in Bioinformatics), vol. 7685, pp. 81-93, Springer, Berlin, Germany, 2013.

[66] P. C. Chen, T. Jeng, Y. S. Deng, and S. F. Chien, "GreenSense: developing persuasive service technology by integrating mobile devices and social interaction for sustainable and healthy behavior," in Lecture Notes in Computer Science (including subseries Lecture Notes in Artificial Intelligence and Lecture Notes in Bioinformatics), vol. 8010, pp. 345-354, Springer, Berlin, Germany, 2013.

[67] K. Williams and C. Breazeal, "Reducing driver task load and promoting sociability through an affective intelligent driving agent (AIDA)," in Human-Computer Interaction-INTERACT 2013, P. Kotzé, G. Marsden, G. Lindgaard et al., Eds., vol. 8120, pp. 619-626, Springer, Berlin, Germany, 2013.

[68] S. Schneegass, B. Pfleging, N. Broy, A. Schmidt, and F. Heinrich, "A data set of real world driving to assess driver workload," in Proceedings of the 5th International Conference on Automotive User Interfaces and Interactive Vehicular Applications, Automotive 2013, pp. 150-157, Eindhoven, Netherlands, October 2013.

[69] B. Pfleging, S. Schneegass, and A. Schmidt, "Exploring user expectations for context and road video sharing while calling and driving," in Proceedings of the 5th International Conference on Automotive User Interfaces and Interactive Vehicular Applications, Automotive 2013, pp. 132-139, Eindhoven, Netherlands, October 2013.

[70] S. Nawaz, C. Efstratiou, and C. Mascolo, "Parksense: a smartphone based sensing system for on-street parking," 2013.

[71] P. Tchankue, J. Wesson, and D. Vogts, "Using machine learning to predict the driving context whilst driving," 2013.

[72] F. Cellina, A. Förster, D. Rivola, L. Pampuri, R. Rudel, and A. E. Rizzoli, "Using smartphones to profile mobility patterns in a living lab for the transition to E-mobility," in Environmental Software Systems. Fostering Information Sharing, J. Hřebíček, G. Schimak, M. Kubásek et al., Eds., vol. 413, pp. 154-163, Springer, Berlin, Germany, 2013.
[73] DriveSafe Free, 2021, https://apps.apple.com/us/app/ drivesafe-free/id657809944.

[74] Good Driver - Driving Tester, 2021, https://play.google.com/ store/apps/details?id=com.ovil.gooddriver.

[75] R. Klemke, M. Kravcik, and F. Bohuschke, "Energy-efficient and safe driving using a situation-aware gamification approach in logistics," in Lecture Notes in Computer Science (including subseries Lecture Notes in Artificial Intelligence and Lecture Notes in Bioinformatics), vol. 8605, pp. 3-15, Springer, Berlin, Germany, 2014.

[76] M. D. Rodríguez, R. R. Roa, J. E. Ibarra, and C. M. Curlango, "In-car ambient displays for safety driving gamification," ACM's International Conference Proceedings Series, pp. 2629, 2014.

[77] M. D. Rodríguez, J. E. Ibarra, J. R. Roa, C. M. Curlango, L. F. Bedoya, and H. D. Montes, "Ambient gamification of automobile driving to encourage safety behaviors," Lecture Notes in Computer Science (including subseries Lecture Notes in Artificial Intelligence and Lecture Notes in Bioinformatics), Springer, vol. 8867, pp. 37-43, , Berlin, Germany, 2014.

[78] S. Diewald, P. Lindemann, A. Moller, T. Stockinger, M. Koelle, and M. Kranz, "Gamified training for vehicular user interfaces-effects on drivers' behavior," in Proceedings of the 2014 International Conference on Connected Vehicles and Expo (ICCVE), pp. 250-257, Vienna, Austria, November 2014.

[79] DriveProfiler UBI, 2021, https://play.google.com/store/apps/ details?id=com.scope.mzonedriver.

[80] Drive Safe \& Saveâ, 2021, https://play.google.com/store/ apps/details?id=com.statefarm.dssm.

[81] DriveSmart | Are you a good driver?”, 2 021, https://play. google.com/store/apps/details?id=com.drivesmart.

[82] J. H. Hong, B. Margines, and A. K. Dey, "A smartphonebased sensing platform to model aggressive driving behaviors," in Proceedings of the Conference on Human Factors in Computing Systems, pp. 4047-4056, Toronto, Canada, April 2014.

[83] S. Aleyadeh, S. M. A. Oteafy, and H. S. Hassanein, "Scalable transportation monitoring using the smartphone road monitoring (SRoM) System," in Proceedings of the 5th ACM Symposium on Development and Analysis of Intelligent Vehicular Networks and Applications (DIVANet 2015), pp. 43-50, Cancun, Mexico, November 2015.

[84] S. Hu, L. Su, H. Liu, H. Wang, and T. F. Abdelzaher, "Smartroad: smartphone-based crowd sensing for traffic regulator detection and identification," ACM Transactions on Sensor Networks, vol. 11, no. 4, 2015.

[85] O. Dehzangi and C. Williams, "Multi-modal biological driver monitoring via ubiquitous wearable body sensor network," 2015.

[86] X. Hu, J. Deng, J. Zhao et al., "SAfeDJ: a crowd-cloud codesign approach to situation-aware music delivery for drivers," ACM Transactions on Multimedia Computing, Communications, and Applications, vol. 12, no. 1s, pp. 1-24, 2015.

[87] Z. Chen, J. Yu, Y. Zhu, Y. Chen, and M. Li, “D3: abnormal driving behaviors detection and identification using smartphone sensors," in Proceedings of the 2015 12th Annual IEEE International Conference on Sensing, Communication, and Networking, SECON 2015, pp. 524-532, Seattle, WA, USA, June 2015.

[88] AutoWiz, 2021, https://play.google.com/store/apps/details? $\mathrm{id}=$ com.sigmatechlabs.autowiz. 
[89] Drive ULU, 2021, https://play.google.com/store/apps/ details?id=io.ulu.ulu.

[90] DriveAssist," 2021, https://play.google.com/store/apps/ details? $\mathrm{id}=$ com.stg.driveassist.

[91] Motovate, 2021, https://play.google.com/store/apps/details? id=ninja.text.

[92] My_BRIDGE, 2021, https://play.google.com/store/apps/ details?id=com.pembridge.newmybridge.

[93] Azuga FleetMobile, 2021, https://play.google.com/store/ apps/details?id=com.azuga.smartfleet.

[94] Better Driver, 2021, https://play.google.com/store/apps/ details?id=com.d3t.betterdriver.

[95] M. Krause, S. Weichelt, and K. Bengler, "Malfunction of a traffic light assistant application on a smartphone," in ACM International Conference Proceeding Series, pp. 1-5, 2015.

[96] Carot-Upgrade to a Smart Car, 2021, https://play.google. com/store/apps/details?id=com.carot.iconnect.

[97] Mandata SmartDrive, 2021, https://play.google.com/store/ apps/details?id=com.mandata.advancedservices. drivertraininghub.android.

[98] Root Car Insurance: Good drivers save money, 2021, https:// play.google.com/store/apps/details?id=com.joinroot.root.

[99] AAMI Safe Driver, 2021, https://apkpure.com/aami-safedriver/au.com.aami.safedriver.

[100] Safer Schools Safe Drive-Applications sur Google Play, 2021, https://play.google.com/store/apps/details?id=com. driveprofiler.saferschools.

[101] I. Lashkov, A. Smirnov, A. Kashevnik, and V. Parfenov, "Ontology-based approach and implementation of ADAS system for mobile device use while driving," Communications in Computer and Information Science, vol. 518, pp. 117-131, 2015.

[102] O. Orfila, G. Saint Pierre, and M. Messias, "An android based ecodriving assistance system to improve safety and efficiency of internal combustion engine passenger cars," Transportation Research Part C: Emerging Technologies, vol. 58, pp. 772-782, 2015.

[103] B. Predic and D. Stojanovic, "Enhancing driver situational awareness through crowd intelligence," Expert Systems with Applications, vol. 42, no. 11, pp. 4892-4909, Jul. 2015.

[104] T. Schneeberger, S. von Massow, M. M. Moniri, A. Castronovo, C. Müller, and J. Macek, "Tailoring mobile apps for safe on-road usage: how an interaction concept enables safe interaction with hotel booking, news, wolfram alpha and Facebook," in Proceedings of the 7th International Conference on Automotive User Interfaces and Interactive Vehicular Applications, pp. 241-248, Nottingham, UK, September 2015.

[105] F. Seraj, N. Meratnia, K. Zhang, P. J. M. Havinga, and O. Turkes, "A smartphone based method to enhance road pavement anomaly detection by analyzing the driver behavior," in Proceedings of the 2015 ACM International Joint Conference on Pervasive and Ubiquitous Computing and the Proceedings of the 2015 ACM International Symposium on Wearable Computers, pp. 1169-1178, Osaka, Japan, September 2015.

[106] C. Atzl, A. Meschtscherjakov, S. Vikoler, and M. Tscheligi, "Bet4EcoDrive," in Persuasive Technology, T. MacTavish and S. Basapur, Eds., vol. 9072, pp. 71-82, Springer International Publishing, Cham, Switzerland, 2015.

[107] E. Ibragimova, N. Mueller, A. Vermeeren, and P. Vink, “The smart steering wheel cover: motivating safe and efficient driving," in Proceedings of the CHI Conference on Human
Factors in Computing Systems (CHI '15), p. 169, Seoul, Republic of Korea, April 2015.

[108] A. Ghose, T. Banerjee, A. Chowdhury, T. Chakravarty, and V. Chandel, "An enhanced automated system for evaluating Harsh driving using smartphone sensors," in ACM International Conference Proceeding Series, pp. 1-6, Springer, Berlin, Germany, 2016.

[109] K. Bahadoor and P. Hosein, "Application for the detection of dangerous driving and an associated gamification framework," in Proceedings of the 2016 IEEE 4th International Conference on Future Internet of Things and Cloud Workshops (FiCloudW), pp. 276-281, Vienna, Austria, August 2016.

[110] Drive Master, 2021, https://play.google.com/store/apps/ details?id=com.income.drivemaster.

[111] DriveProfiler Connected Car, 2021, https://play.google.com/ store/apps/details?id=com.scope.dppoc.

[112] Driver Behaviour Scorecard, 2021, https://play.google.com/ store/apps/details?id=com.seon.ds2scorecard.

[113] Mentor $\hat{A}^{\circledR}$ by eDriving Business, 2021, https://play.google. com/store/apps/details?id=com.edriving.mentor.business.

[114] Mia-your mobile insurance app, 2021, https://appadvice. com/app/mia-your-mobile-insurance-app/1131139169.

[115] SAFE 2 SAVE, 2021, https://play.google.com/store/apps/ details?id=org.safe2save.safe2save.

[116] TrueMotion Business, 2021, https://play.google.com/store/ apps/details?id=com.gotruemotion.ubi.

[117] TrueMotion Family Safe Driving, 2021, https://play.google. com/store/apps/details?id=io.cens.family.

[118] ZEPHYR powered by Modus, 2021, https://play.google.com/ store/apps/details?id=com.modusgo.modusfleet.

[119] My driving discount-intact, 2021, https://play.google.com/ store/apps/details?id=ca.intact. mydrivingdiscount.

[120] M. Sysoev, A. Kos, and M. Pogačnik, "Smart driving: influence of context and behavioral data on driving style," in Lecture Notes in Computer Science (including subseries Lecture Notes in Artificial Intelligence and Lecture Notes in Bioinformatics), vol. 9870, pp. 141-151, Springer, Berlin, Germany, 2016.

[121] A. Vaezipour, A. Rakotonirainy, and N. Haworth, "Design of a gamified interface to improve fuel efficiency and safe driving," in Design, User Experience, and Usability: Novel User Experiences, A. Marcus, Ed., vol. 9747, pp. 322-332, Springer International Publishing, Cham, Switzerland, 2016.

[122] I. Boutsis and V. Kalogeraki, "CrowdAlert: a mobile app for event reporting and user alerting in real-time," 2016.

[123] FGL DriveTracker, 2021, https://play.google.com/store/ apps/details?id=com.motolingo.motocarma.freshgreenlight.

[124] OSeven, 2021, https://play.google.com/store/apps/details? id=io.oseven.safedriving.

[125] Autobrain, 2021, https://play.google.com/store/apps/details? id=com. autobrain. android.

[126] CarVi, 2021, https://play.google.com/store/apps/details? $\mathrm{id}=$ com.getcarvi.igg\&hl=en\&gl=us.

[127] Betterways: GPS Fleet tracking, 2021, https://play.google. com/store/apps/details?id=com.betterways.

[128] F. Steinberger, R. Schroeter, and D. Babiac, "Engaged drivers-safe drivers: gathering real-time data from mobile and wearable devices for safe-driving apps," Automotive User Interfaces,Human-Computer Interaction Series, Springer, Berlin, Germany, pp. 55-76, 2017.

[129] Y. Zhao et al., "GreenDrive: a smartphone-based intelligent speed adaptation system with real-time traffic signal prediction," in Proceedings of the 2017 ACM/IEEE 8th 
International Conference on Cyber-Physical Systems, ICCPS 2017 (Part of CPS Week), pp. 229-238, Pittsburgh, PA, USA, April 2017.

[130] DriveQuant, 2021, https://play.google.com/store/apps/ details?id=com.drivequant.

[131] Driverlink, 2021, https://play.google.com/store/apps/details? $\mathrm{id}=$ com.ideabits.driverlink.

[132] MyRoadChallenge, 2021, https://play.google.com/store/ apps/details?id=com.michelin.myrc.

[133] RoadChek, 2021, https://play.google.com/store/apps/details? $\mathrm{id}=\mathrm{fq}$.HoursOfService.

[134] SmarterDriver, 2021, https:/play.google.com/store/apps/ details?id=com.masternaut.smarterdriver.

[135] Snjallari BÃ-lar, 2021, https://play.google.com/store/apps/ details?id=com.modusgo.ubi.siminnfleet.

[136] HiRoadÂ ${ }^{\circledR}, \quad 2021$, https://play.google.com/store/apps/ details?id=xyz.blueowl.mobile.hiroad.

[137] KnowYourDrive, 2021, https://apps.apple.com/us/app/ knowyourdrive/id1235726818.

[138] Accuscore-Driver Scoring, 2021, https://play.google.com/ store/apps/details?id=xyz.accuscore.fleet.

[139] AVIS SafeDrive, 2021, https://play.google.com/store/apps/ details?id=za.co.vitalitydrive.avis.

[140] H. Chin, H. Zabihi, S. Park, M. Y. Yi, and U. Lee, "Watchout: facilitating safe driving behaviors with social support," in Proceedings of the 2017 CHI Conference Extended Abstracts on Human Factors in Computing Systems, pp. 2459-2465, Denver, CO, USA, May 2017.

[141] Dashcam Insurance Deals Navigation \& AI Safety, 2021, https://play.google.com/store/apps/details?id=com. trydriver.driver.

[142] Drive Safely by Autocillin, 2021, https://play.google.com/ store/apps/details?id=com.raxeltelematics.adira.

[143] Driveway-Smart Driving, 2021, https://play.google.com/ store/apps/details?id=ai.driveway.seven.

[144] Raxel Drive, 2021, https://play.google.com/store/apps/ details?id=com.raxeltelematics.drive2.

[145] https://play.google.com/store/apps/details?id=com.modusgo. ubi.readyfleet Ready Fleet Tracking, 2021.

[146] SafeDriver-Driver Behaviour, 2021, https://play.google.com/ store/apps/details?id=com.webtrack.safedriver.sa.

[147] Tryg Drive, 2021, https://play.google.com/store/apps/details? $\mathrm{id}=$ org.leanportal.tryggdkjunior.

[148] Drive with Safety, 2021, https://play.google.com/store/apps/ details?id=com.gotruemotion.tmfb.safety.

[149] Teen Safe Driver ${ }^{\text {SM }}$, 2021, https://play.google.com/store/ apps/details?id=com.gotruemotion.tmfb.amfam.

[150] Travelers IntelliDrive $\tilde{A}^{\prime} \hat{A}{ }^{\circledR}, 2021$, https://play.google.com/store/ apps/details? $\mathrm{id}=$ com.gotruemotion.ubi.travelers.intellidrive.

[151] S. Park, E. S. Ilincai, J. Oh, S. Kwon, R. Mizouni, and U. Lee, "Facilitating pervasive community policing on the road with mobile roadwatch," in Proceedings of the 2017 CHI Conference Extended Abstracts on Human Factors in Computing Systems, pp. 3538-3550, Denver, CO, USA, May 2017.

[152] CarX-Connected Car, 2021, https://play.google.com/store/ apps/details?id=io.carx.app.carx.

[153] E. Çano, R. Coppola, E. Gargiulo, M. Marengo, and M. Morisio, "Mood-based on-car music recommendations," in Industrial Networks and Intelligent Systems, L. A. Maglaras, H. Janicke, and K. Jones, Eds., vol. 188, pp. 154-163, Springer International Publishing, Cham, Switzerland, 2017.

[154] A. Dirin, T. H. Laine, and M. Nieminen, "Sustainable usage through emotional engagement: a user experience analysis of an adaptive driving school application," Cognition, Technology \& Work, vol. 19, no. 2-3, pp. 303-313, 2017.

[155] F. Steinberger, R. Schroeter, and C. N. Watling, "From road distraction to safe driving: evaluating the effects of boredom and gamification on driving behaviour, physiological arousal, and subjective experience," Computers in Human Behavior, vol. 75, pp. 714-726, 2017.

[156] P. Di Lena, S. Mirri, C. Prandi, P. Salomoni, and G. Delnevo, "In-vehicle human machine interface: an approach to enhance eco-driving behaviors," in Proceedings of the 2017 ACM Workshop on Interacting with Smart Objects (SmartObject 2017), pp. 7-12, Limassol, Cyprus, March 2017.

[157] A. Mosenia, J. F. Bechara, T. Zhang, P. Mittal, and M. Chiang, "ProCMotive: bringing programmability and connectivity into isolated vehicles," Proceedings of the ACM Interactive, Mobile, Wearable Ubiquitous Technology, vol. 2, no. 1, pp. 1-31, 2018.

[158] F. Steinberger, R. Schroeter, M. Foth, and D. Johnson, "Designing gamified applications that make safe driving more engaging," in Proceedings of the CHI Conference on Human Factors in Computing Systems, pp. 2826-2839, Austin, TX, USA, May 2017.

[159] DriveProfiler II, 2021, https://apps.apple.com/be/app/ driveprofiler-ii/id1195608550.

[160] A. V. D. da Silva, L. Borges, and V. Vieira, "CDNA-a contextaware notification system for driver interruption," in Proceedings of the 17th Brazilian Symposium on Human Factors in Computing Systems, New York, NY, USA, October 2018.

[161] E. Panizzi and D. Calvitti, "A framework to enhance the user experience of car mobile applications," in Proceedings of the 20th International Conference on Human-Computer Interaction with Mobile Devices and Services (MobileHCI 2018beyond Mobile: the Next 20 Years), pp. 245-252, Conference Proceedings Adjunct, Barcelona, Spain, September 2018.

[162] Axo Driver, 2021, https://play.google.com/store/apps/ details?id=synox.xamarin.android.axodriver.

[163] CoPiloTT, 2021, https://play.google.com/store/apps/details? id=air.com.maritimefinancial.copilott.

[164] DriverCom, 2021, https://play.google.com/store/apps/ details?id=com.carfics.drivercom.

[165] Fleetify, 2021, https://play.google.com/store/apps/details? id=uk.co.fleetify.app.

[166] FMS-Driver, 2021, https://play.google.com/store/apps/ details?id=com.cerebrox.driver.

[167] I-Sticker, 2021, https://play.google.com/store/apps/details? $\mathrm{id}=$ com.popapp.isticker.

[168] Motus1, 2021, https://play.google.com/store/apps/details? $\mathrm{id}=$ com.tourmaline.esi.

[169] Safeco RightTrack, 2021, https://play.google.com/store/apps/ details?id=com.libertymutual.uscm.safeco. righttrack\&hl=en\&gl=us.

[170] NJM SafeDrive, 2021, https://play.google.com/store/apps/ details?id=com.NJM.NJMSafeDrive.

[171] S. Helvaci, A. Senova, G. Kar, and S. Gören, "Improving driver behavior using gamification," Lecture Notes in Computer Science, vol. 10995, pp. 193-204, 2018.

[172] T. Tanaka, "Driving behavior improvement through driving support and review support from driver agent," in Proceedings of the 6th International Conference on HumanAgent Interaction, pp. 36-44, Southampton, UK, December 2018.

[173] J. Y. Park, J. P. Yun, and D. H. Lee, "WheelLogger: driver tracing using smart watch," in Information Security 
Applications, B. B. Kang and T. Kim, Eds., vol. 10763, pp. 87-100, Springer International Publishing, Cham, Switzerland, 2018.

[174] Actua Learning, 2021, https://play.google.com/store/apps/ details?id=com.airteach.actualearning.

[175] Chubb at the Wheel ${ }^{\mathrm{TM}}$, https://play.google.com/store/apps/ details?id=com.chubb.atthewheel.

[176] Drive Safe, 2021, https://play.google.com/store/apps/details? id=com.gic.drivesafe

[177] Drivewise Canada, 2021, https://play.google.com/store/ apps/details?id=com.modusgo.drivewise.

[178] Ideal Driver, 2021, https://play.google.com/store/apps/ details?id=fr.openium.ddi.

[179] Jido Sense, 2021, https://play.google.com/store/apps/details? $\mathrm{id}=$ ai.tangerine.jido.sense.

[180] Just Drive, 2021, https://play.google.com/store/apps/details? $\mathrm{id}=$ com. angularfirebase.justdrive.

[181] Mentor ${ }^{\circledR}$ DSP by eDrivingSM, 2021, https://play.google. com/store/apps/details?id=com.edriving.mentor.amazon.

[182] MZone Fleet, 2021, https://play.google.com/store/apps/ details?id=com.Scopetechnology.MZoneFleet.

[183] A. U. Nambi, A. Virmani, and V. Padmanabhan, "FarSight: a smartphone-based vehicle ranging system," Proceedings of the ACM on Interactive, Mobile, Wearable and Ubiquitous Technologies, vol. 2, no. 4, pp. 1-22, 2018.

[184] Safe Drive: Text Blocker while Driving, 2021, https://play. google.com/store/apps/details?id=com.safedrive.safedrive.

[185] Safe Driver Solutions, 2021, https://play.google.com/store/ apps/details?id=io.safedriver.

[186] Selective Drive, 2021, https://play.google.com/store/apps/ details?id=com.modusgo.selectiveapp.

[187] Xefyr-Drive Safe, Get Rewards, 2021, https://play.google. com/store/apps/details?id=com.xefyr.ridez.

[188] Xemplar Drive, 2021, https://play.google.com/store/apps/ details?id=com.xemplar.drive.

[189] Nauto Driver App, 2021, https://play.google.com/store/ apps/details?id=com.nauto.driverapp.

[190] Cayman's Safest Driver, 2021, https://play.google.com/store/ apps/details?id=ky.saxonmg.safestdriver.

[191] ERIE YourTurn, 2021, https://play.google.com/store/apps/ details?id=com.erieinsurance. yourturn.

[192] Steer Clear, 2021, https://play.google.com/store/apps/ details?id=com.statefarm.sfsteerclear.

[193] D. Raptis, J. Iversen, T. H. Mølbak, and M. B. Skov, "DARA: assisting drivers to reflect on how they hold the steering wheel," 2018.

[194] Y. S. Cohen and E. Shmueli, "Money drives: can monetary incentives based on real-time monitoring improve driving behavior?," Proceedings of the ACM on Interactive, Mobile, Wearable and Ubiquitous Technologies, vol. 1, no. 4, pp. 1-22, 2018.

[195] Targify-Young Driver Safety dans l'App Store, 2021, https://apps. apple.com/fr/app/targify-young-driver-safety/id1392391372.

[196] SmartWitness-Analytics-Applications sur Google Play, 2021, https://play.google.com/store/apps/details?id=com. smartwitness.smartanalytics.

[197] C.-W. You, Y.-F. Lin, Y. Chuang et al., "SoberMotion: leveraging the force of probation officers to reduce the risk of DUI recidivism," Proceedings of the ACM on Interactive, Mobile, Wearable and Ubiquitous Technologies, vol. 2, no. 3, pp. 1-34, 2018.

[198] R. Bhandari, A. U. Nambi, V. N. Padmanabhan, and B. Raman, "DeepLane: camera-assisted GPS for driving lane detection," in Proceedings of the 5th Conference on Systems for Built Environments (BuildSys 2018), pp. 73-82, Shenzen, China, November 2018.

[199] A. Kaci, A. Nacef, and A. Henni, "Mobile cloud system for road safety," in ACM International Conference Proceeding Series, pp. 132-136, ACM, New York, NY, USA, 2018.

[200] B. Bose, J. Dutta, S. Ghosh, P. Pramanick, and S. Roy, "Smartphone based system for real-time aggressive driving detection and marking rash driving-prone areas," ACM International Conference Proceeding Series, ACM, New York, NY, USA, 2018.

[201] L. Jiang, X. Lin, X. Liu, C. Bi, and G. Xing, "SafeDrive: detecting distracted driving behaviors using wrist-worn devices," Proceedings of the ACM on Interactive, Mobile, Wearable and Ubiquitous Technologies, vol. 1, no. 4, pp. 1-22, 2018.

[202] A. Dahlinger, F. Wortmann, B. Ryder, and B. Gahr, "The impact of abstract vs. concrete feedback design on behavior insights from a large eco-driving field experiment," in Proceedings of the 2018 CHI Conference on Human Factors in Computing Systems, pp. 1-11, Montreal, QC, Canada, April 2018.

[203] Amber Driver, 2021, https://play.google.com/store/apps/ details?id=com. amberconnect.driver.

[204] Y. Xie, F. Li, Y. Wu, S. Yang, and Y. Wang, "D3-Guard: acoustic-based drowsy driving detection using smartphones," in Proceedings of the IEEE Conference on Computer Communications (IEEE INFOCOM 2019), pp. 1225-1233, Paris, France, April 2019.

[205] N. Kosmyna, C. Morris, T. Nguyen et al., "Designing EEG and EOG compatible glasses for physiological sensing and feedback in the car," in Proceedings of the 11th International ACM Conference on Automotive User Interfaces and Interactive Vehicular Applications, Automotive 2019, pp. 355-368, Utrecht, Netherlands, September 2019.

[206] DriveProfiler BLE, 2021, https://apps.apple.com/in/app/ driveprofiler-ble/id1449570922.

[207] DrivingSMART, 2021, https://play.google.com/store/apps/ details?id=eu.astrata.drivingsmart.

[208] IdealDriverPro, 2021, https://play.google.com/store/apps/ details?id=com.michelin.idealdriverpro.

[209] IGI Drive, 2021, https://play.google.com/store/apps/details? $\mathrm{id}=$ com.igidrive.androidapp.

[210] LÉA by DriveQuant, 2021, https://play.google.com/store/ apps/details?id=com.drivequant.lea.

[211] MozWavelength, 2021, https://apps.apple.com/kw/app/ mozwavelength/id1459848667.

[212] My Ecodrive, 2021, https://play.google.com/store/apps/ details?id=com.emixis.myecodrive.

[213] Precision Car, 2021, https://play.google.com/store/apps/ details?id=com.innovativeapplications.precisioncar.

[214] Driveology ${ }^{\circledR}, \quad 2021$, https://play.google.com/store/apps/ details?id=com.fbfs.mobile.telematics.

[215] Know before \& Drive Safe Breaker Pothole Alert, 2021, https://play.google.com/store/apps/details?id=com. knowbefore.speedbreaker\&hl=en\&gl=us.

[216] R. Massoud, F. Bellotti, R. Berta, A. De Gloria, and S. Poslad, "Eco-driving profiling and behavioral shifts using IoT vehicular sensors combined with serious games," in Proceedings of the 2019 IEEE Conference on Games (CoG), pp. 1-8, London, UK, August 2019.

[217] OnMyWay: Drive Safe, Get Paid, 2021, https://play.google. com/store/apps/details?id=com.onmyway. mobi\&hl=en\&gl=us. 
[218] Drive Safe-Jamaica, 2021, https://play.google.com/store/ apps/details?id=com.transportauthority\&hl=en\&gl=us.

[219] Drive Safely, 2021, https://play.google.com/store/apps/ details?id=ru.igla.drivesafely\&hl=en $\& \mathrm{gl}=\mathrm{us}$.

[220] Autokit, 2021, https://play.google.com/store/apps/details? id=com.autokit\&pcampaignid=MKT-Other-global-all-co-prtnrpy-PartBadge-Mar2515-1.

[221] AI Smart Driving, 2021, https://play.google.com/store/apps/ details?id=com.i2atechs.i2aallsensors.

[222] AVIS SafeDrive Netherlands, 2021, https://play.google.com/ store/apps/details?id=za.co.vitalitydrive.avis.safedrive.nl.

[223] COUNTRY Financial DriverIQ, 2021, https://play.google. $\mathrm{com} /$ store/apps/details?id=com.countryfinancial.driveriq. drivingapp.

[224] Drive Safe Club-Smart Dash Cam, 2021, https://play.google. $\mathrm{com} /$ store/apps/details?id=hitech.robotic.systemzz.

[225] Drive-Class, 2021, https://play.google.com/store/apps/ details?id=me.com.driveadi.

[226] Driver Module, 2021, https://play.google.com/store/apps/ details?id=com.boodskap.driverapp.

[227] I. Warren, A. Meads, C. Wang, and R. Whittaker, "Monitoring driver behaviour with BackPocketDriver," in Mobile Web and Intelligent Information Systems, I. Awan, M. Younas, P. Ünal, and M. Aleksy, Eds., vol. 11673, pp. 57-70, Springer International Publishing, Cham, Switzerland, 2019.

[228] Driving Avatar, 2021, https://play.google.com/store/apps/ details?id=com.autoliv.drivingavatar_v2.

[229] Jido Lite, 2021, https://play.google.com/store/apps/details? id=ai.tangerine.jido.lite.

[230] LiveGPS DRIVER, 2021, https://play.google.com/store/apps/ details?id=com.livegps.driverlink.

[231] https://play.google.com/store/apps/details?id=com.modusgo. readywireless Ready Fleet, 2021.

[232] SAFE.T Prevention, 2021, https://play.google.com/store/ apps/details?id=eu.safet.safetapp.

[233] SafeMode Driver, 2021, https://play.google.com/store/apps/ details?id=com.safemode.driver.

[234] Safest Driverâđ, 2021, https://play.google.com/store/apps/ details?id=com.safestdriver.drivingapp.

[235] Wavyn-safe driving \& collision alerts, 2021, https://play. google.com/store/apps/details?id=com.wavyn.

[236] Maas Driver: Drive \& Earn, 2021, https://play.google.com/ store/apps/details?id=com.zemaasdriver.

[237] DriveEasy by GEICO, 2021, https://play.google.com/store/ apps/details?id=com.geico.telematics.

[238] S. R. G. Christopoulos, S. Kanarachos, and A. Chroneos, "Learning driver braking behavior using smartphones, neural networks and the sliding correlation coefficient: road anomaly case study," IEEE Transactions on Intelligent Transportation Systems, vol. 20, no. 1, pp. 65-74, 2019.

[239] RiVE: Safe Driving, 2021, https://play.google.com/store/ apps/details?id=com.riveanddrive. android.

[240] State Auto Safety $360^{\circledR}$ Mobile, 2021, https://play.google. $\mathrm{com} /$ store/apps/details?id=com.stateauto.safety 360 .

[241] SparkT-Applications sur Google Play, 2021, https://play. google.com/store/apps/details?id=pl.sparkbit.sparkt.

[242] E. G. Mantouka, E. N. Barmpounakis, and E. I. Vlahogianni, "Identifying driving safety profiles from smartphone data using unsupervised learning," Safety Science, vol. 119, pp. 84-90, 2019.

[243] E. Papadimitriou, A. Argyropoulou, D. I. Tselentis, and G. Yannis, "Analysis of driver behaviour through smartphone data: the case of mobile phone use while driving," Safety Science, vol. 119, pp. 91-97, 2019.

[244] S. Bianco, P. Napoletano, and R. Schettini, "Multimodal car driver stress recognition," in ACM International Conference Proceeding Series, pp. 302-307, ACM, New York, NY, USA, 2019.

[245] A. U. Nambi, I. Mehta, A. Ghosh, V. Lingam, and V. N. Padmanabhan, "ALT: towards automating driver license testing using smartphones," in Proceedings of the 17th Conference on Embedded Networked Sensor Systems (SenSys 2019), pp. 29-42, New York, NY, USA, November 2019.

[246] W. Zhong, Q. Suo, F. Ma et al., "A reliability-aware vehicular crowdsensing system for pothole profiling," Proceedings of the ACM on Interactive, Mobile, Wearable and Ubiquitous Technologies, vol. 3, no. 4, pp. 1-26, 2019.

[247] G. Lechner, M. Fellmann, A. Festl et al., "A lightweight framework for multi-device integration and multi-sensor fusion to explore driver distraction," in Lecture Notes in Computer Science (including subseries Lecture Notes in Artificial Intelligence and Lecture Notes in Bioinformatics), vol. 11483, pp. 80-95, Springer, Berlin, Germany, 2019.

[248] A. Vaezipour, A. Rakotonirainy, N. Haworth, and P. Delhomme, "A simulator study of the effect of incentive on adoption and effectiveness of an in-vehicle human machine interface," Transportation Research Part F: Traffic Psychology and Behaviour, vol. 60, pp. 383-398, 2019.

[249] S. Nousias, C. Tselios, D. Bitzas et al., "Exploiting gamification to improve eco-driving behaviour: the GamECAR approach," Electronic Notes in Theoretical Computer Science, vol. 343, pp. 103-116, 2019.

[250] C. Bi and G. Xing, "RAMT: real-time attitude and motion tracking for mobile devices in moving vehicle," Proceedings of the ACM Interactive, Mobile, Wearable Ubiquitous Technology, vol. 3, no. 2, pp. 1-21, 2019.

[251] Autoskill, 2021, https://play.google.com/store/apps/details? id=com.hidevmobile.AutoSkill.

[252] Coloride, 2021, https://play.google.com/store/apps/details? $\mathrm{id}=$ com.swissre.srdrive.

[253] LifeDrive BLE, 2021, https://play.google.com/store/apps/ details?id=com.scope.lifeDriveBLE.

[254] Driver Distraction Alert, 2021, https://play.google.com/ store/apps/details?id=com.gma. thedriverdistraction \&hl=en\&gl=us.

[255] Drive Wiser Safe \& Secure, 2021, https://play.google.com/ store/apps/details?id=uk.co.bewiser.telematics.

[256] E. Anagnostopoulou, J. Urbančič, E. Bothos et al., "From mobility patterns to behavioural change: leveraging travel behaviour and personality profiles to nudge for sustainable transportation," Journal of Intelligent Information Systems, vol. 54, no. 1, pp. 157-178, 2020.

[257] T. Xing, Q. Wang, C. Q. Wu, W. Xi, and X. Chen, "Dwatch: a reliable and low-power drowsiness detection system for drivers based on mobile devices," ACM Transactions on Sensor Networks, vol. 16, no. 4, pp. 1-22, 2020.

[258] DriveRecorder AI Safe-Driving, 2021, https://play.google. com/store/apps/details?id=com.cyberih. aidriverecorder\&hl=en\&gl=us.

[259] Safe Drive AI App-Secure Drive with AI, 2021, https://play. google.com/store/apps/details?id=com.mukeshbangar. muksbotdrivesafely\&hl=en\&gl=us.

[260] Awake: Drowsy Driving," 2021, https://apps.apple.com/us/ app/awake-drowsy-driving/id1493097609.

[261] Drowsy Alert: Wake Up, 2021, https://apps.apple.com/us/ app/drowsy-alert-wake-up/id1530140693. 
[262] DrivActiv iSight, 2021, https://play.google.com/store/apps/ details?id=com.drivesmart.drivactiv.

[263] Hach Driving Performance, 2021, https://play.google.com/ store/apps/details?id=com.hach.fleet.

[264] Mpitsa Driver, 2021, https://play.google.com/store/apps/ details?id=com. $\mathrm{mpitsadrive.}$.driver.

[265] Accessor Safe Drive, 2021, https://play.google.com/store/ apps/details?id=com.accessor.accessortelematics.

[266] DriveSafe, 2021, https://play.google.com/store/apps/details? id=com.qmic.mydriving.

[267] Who is in the Driver' Seat?, 2021, https://play.google.com/ store/apps/details?id=edu.tamu.tti.yds.

[268] Rockingham Safe Driving App, 2021, https://play.google. com/store/apps/details?id=com.rockingham.test_drive.

[269] Safe Drive, 2021, https://play.google.com/store/apps/details? $\mathrm{id}=$ com.safe.drive.

[270] S. Arumugam and R. Bhargavi, "A survey on driving behavior analysis in usage based insurance using big data," Journal of Big Data, vol. 6, no. 1, 2019.

[271] J. B. Torous, S. R. Chan, S. Y.-M. T. Gipson et al., "A hierarchical framework for evaluation and informed decision making regarding smartphone apps for clinical care," Psychiatric Services, vol. 69, no. 5, pp. 498-500, 2018.

[272] T. Dehling, F. Gao, S. Schneider, and A. Sunyaev, "Exploring the far side of mobile health: information security and privacy of mobile health apps on iOS and android," JMIR mHealth uHealth, vol. 3, no. 1, p. e8, 2015.

[273] S. M. Schueller, J. J. Washburn, and M. Price, "Exploring mental health providers' interest in using web and mobilebased tools in their practices," Internet Interventions, vol. 4, pp. 145-151, 2016.

[274] E. Tzirakis, F. Zannikos, and S. Stournas, "Impact of driving style on fuel consumption and exhaust emissions: defensive and aggressive driving style," 2007.

[275] M. M. Elaish, N. A. Ghani, L. Shuib, and A. Al-Haiqi, "Development of a mobile game application to boost students' motivation in learning English vocabulary," IEEE Access, vol. 7, pp. 13326-13337, 2019.

[276] L. M. Bergasa, J. Araluce, E. Romera et al., "Naturalistic driving study for older drivers based on the DriveSafe app," in Proceedings of the 2019 IEEE Intelligent Transportation Systems Conference (ITSC), pp. 1574-1579, Auckland, New Zealand, October 2019.

[277] G. Castignani and T. Derrmann, "Driver behavior profiling using smartphones: a low-cost platform for driver monitoring," 2015.

[278] I. Graydon, E. Beatty, S. Paul, M. N. Us, and J. A. Hauck, "Driver condition estimation apparatus, server, driver information collecting apparatus, and driver condition estimation system," Toyota Motor Corp, vol. 1, no. 12, 2006.

[279] D. Ding, K. Gebel, P. Phongsavan, A. E. Bauman, and D. Merom, "Driving: a road to unhealthy lifestyles and poor health outcomes," PLoS One, vol. 9, no. 6, pp. 1-5, 2014.

[280] C. A. Celis-Morales, D. M. Lyall, P. Welsh et al., "Association between active commuting and incident cardiovascular disease, cancer, and mortality: prospective cohort study," $B M J$, vol. 357, Article ID j1456, 2017.

[281] V. W. S. Cheng, T. Davenport, D. Johnson, K. Vella, and I. B. Hickie, "Gamification in apps and technologies for improving mental health and well-being: systematic review," JMIR Mental Health, vol. 6, no. 6, Article ID e13717, 2019.

[282] G. F. Tondello, A. Mora, and L. E. Nacke, "Elements of gameful design emerging from user preferences," in
Proceedings of the Annu. Symp. Comput. Interact. Play (CHI Play 2017), pp. 129-140, Amsterdam, Netherlands, October 2017.

[283] L. C. Wood, “Gamification, No. September 2014," 2015.

[284] S. Schefer-wenzl and I. Miladinovic, "Teaching software engineering with gamification elements," International Journal of Advanced Corporate Learning (iJAC)International Journal of Advanced Corporate Learning (IJAC), vol. 11, pp. 48-51, 2018.

[285] P. Budapest, P. Budapest, and S. Deterding, "The introduction of gamification," 2002.

[286] L. M. Bergasa, D. Almeria, J. Almazan, J. J. Yebes, and R. Arroyo, "DriveSafe: an app for alerting inattentive drivers and scoring driving behaviors," in Proceedings of the 2014 IEEE Intelligent Vehicles Symposium, pp. 240-245, Dearborn, MI, USA, June 2014.

[287] J. R. Lopez, L. C. Gonzalez, J. Wahlstrom, M. Montes Y Gomez, L. Trujillo, and G. Ramirez-Alonso, "A genetic programming approach for driving score calculation in the context of intelligent transportation systems," IEEE Sensors Journal, vol. 18, no. 17, pp. 7183-7192, 2018.

[288] K. Werbach and D. Hunter, For the Win: How Game Thinking Can Revolutionize Your Business, Wharton Digital Press, Chicago, IL, USA, 2015.

[289] L. S. Ferro, "Gamification with Unity 5. X," 2016.

[290] A. Dorling and F. Mccaffery, "The Gamification of SPICE," 2012. 